Ali, Majd; Ajib, Salman; Karcher, Christian:

Enhancing the amount of cold produced and saving of the required input heat using two different adsorbents together in the adsorption ice production AIP system

Original published in:

Global Journal of Energy Technology Research Updates. - Windsor CT : Avanti Publishers.Com. - 4 (2017), 1, p. 9-25.

Original published: April 01, 2017

ISSN:

2409-5818

DOI:

$10.15377 / 2409-5818.2017 .04 .01 .2$

[Visited:

May 12, 2019]

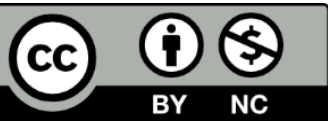

This work is licensed under a Creative Commons AttributionNonCommercial 3.0 Unported license.

To view a copy of this license, visit http://creativecommons.org/licenses/BY-NC/3.0 


\title{
Enhancing the Amount of Cold Produced and Saving of the Required Input Heat using Two Different Adsorbents together in the Adsorption Ice Production AIP System
}

\author{
Majd Ali ${ }^{1, *}$, Salman Ajib² and Christian Karcher $^{3}$
}

${ }^{1}$ Ilmenau Univesity of Technology, Faculty of Mechanical Engineering, Institute of Thermodynamics and Fluid Dynamics, Helmholzring 1, 98693 Ilmenau, Germany

${ }^{2}$ Hochschule Ostwestfalen-Lippe, Department of Renewable Energies and Decentralized Energy Supplying, Wilhelmshöhe 44, D 37671 Höxter, Germany

3/lmenau Univesity of Technology, Faculty of Mechanical Engineering, Institute of Thermodynamics and Fluid Dynamics, Helmholzring 1, 98693 Ilmenau, Germany

\begin{abstract}
A theoretical investigation of the thermal performance (coefficient of performance COP and specific cooling power SCP) of a two bed Adsorption Ice Production AIP system based on the Silica gel-methanol as adsorbentrefrigerant in the first bed and activated carbon-methanol in the second bed is presented in this paper. Two fined-tube heat exchangers were designed (named SG-bed and AC-bed) in order to generate the same desorbed refrigerant amount of $1 \mathrm{~kg}_{\text {meth }}$ and to contain two different adsorbents. The mass transfer limitations from both the two beds and the heat transfer ability between the particles of adsorbents and heat exchanger fins are taken into account in the simulated model based on the linear driving force LDF model. To desorb $1 \mathrm{~kg}_{\text {meth }}$ from the SG-bed and AC-bed a cycle simulation computer program of the AIP system was developed to investigate the effect of desorption temperature $T_{\text {des}}$, adsorption temperature $T_{\text {ads }}$ and the effect of difference of the required desorption/adsorption time on the system performance and on the amount of the ice produced per cycle $\mathrm{m}_{\text {ice. }}$ In the present simulations, the variation of the heat source temperature from 65 to $100^{\circ} \mathrm{C}$ and chilled water temperature from $15^{\circ} \mathrm{C}$ to $25^{\circ} \mathrm{C}$ are taken. The results showed, that the AIP system attains a coefficient of performance COP of $66 \%$ when the AC-bed is working and attains of $44 \%$ when the SG-bed is working. The amount of the ice produced from the system estimated to $6 \mathrm{~kg}$ per cycle $(3 \mathrm{~kg}$ is produced from each of bed), but the $Q_{\text {in }}$ input energy required to activate the AC-bed has been saved by $46 \%$ compared with that required to activate the SG-bed. Although each of the adsorbent beds was filled with different amount of the sorption material, it is found that the mass of the sorption materials inside the both beds has no effect on the cycle time but has important effect on the specific cooling power SCP. The cycle time is strongly dependent on driven temperature of heat exchange fluid, the design of the heat exchanger and the mass transfer coefficient of sorption material $D_{\text {so. }}$. An experimental set up is planned to be built to make validation of the simulation results.
\end{abstract}

Keywords: Adsorption refrigeration machine, adsorption ice production (AIP) system, different adsorbents activated carbon and silica gel, sorption reactor, thermal analysis.

\section{INTRODUCTION}

Adsorption refrigeration systems are an environmentally friendly feasible and alternative technology to the traditional systems [1], because they employ safe and non-polluting refrigeration [2], which can be driven by low-grade energy and have the advantages of mechanical simplicity and high reliability. As a result, it has been attracted much research attention in recent years [3]. The idea of these devices is the reversible physical sorption of a vapor on the surface of a porous solid (desorption of the refrigerant when exposed to heat and adsorption of it during cooling) $[4,5]$.

A big obstacle to development of adsorption refrigeration technology is the low coefficient of

*Address correspondence to this author at the IImenau Univesity of Technology, Faculty of Mechanical Engineering, Institute of Thermodynamics and Fluid Dynamics, Helmholzring 1, 98693 Ilmenau, Germany; Tel: +49367769-2414; E-mail: majd.ali@tu-ilmenau.de performance and the long cycle time to generate the refrigerant which differs based on the working pairs used and the driving temperature. Another problem is that the simplest cycle of an adsorption cooling system works intermittently [6], because the sorption reactor can't work as desorber and adsorber at the same time, which requires time to desorb and adsorb the circulated refrigerant into the condenser and from the evaporator. This means the amount of cold produced per cycle is smaller compared with the cooling systems which work continuously. Research efforts by previous investigators have therefore been focused on improving the performance and finding new composite sorption materials [7]. To produce continuous refrigeration power, multi-bed adsorption cooling systems have been designed [6].

The performance of the adsorption refrigeration systems affected mainly by the operating conditions and the refrigeration energy which strongly dependents on the adsorbent-adsorbate properties such as the 
equilibrium adsorbate concentration by adsorbent $\mathrm{X}_{\mathrm{eq}}$ $[\mathrm{kg} / \mathrm{kg}]$. Many researchers have been interested in studying the effect of operating conditions on the adsorption cooling system based on thermodynamic analyses. Numerical and experimental study has been conducted to investigate the adsorption cooling system with the different working pairs of adsorbent-adsorbate $[8,9]$.

Oertel and Fischer have experimentally investigated two adsorption cooling systems, the first employs with silica gel-water and the second employs with silica gelmethanol as working pairs. They found the lower operation temperature and the faster operation period is for silica gel-methanol system [10].

The analysis of the cooling and adsorption processes was investigated by Ogueke and Anyanwu. The study showed that low condenser pressure increases the adsorption process while the evaporator pressure should be high to increase the adsorption process. They found also the optimum value of initial concentration of methanol was $0.21[\mathrm{~kg} / \mathrm{kg}]$ to obtain the best adsorbing of adsorbate (the maximum concentration was about $0.29[\mathrm{~kg} / \mathrm{kg}])$. The produced ice increased from 0 to about 0.4 [kgice $/ \mathrm{kg}_{\text {sorbent] }}$ [11].

Khan, Sultana, Akisawa and Kashiwagi have investigated a numerical simulation of advanced adsorption chiller and they could improve the performance of the chiller using the mass recovery [12]. Cho and Kim performed theoretical and experimental studies on a silica gel-water adsorption cooling system. The heat transfer rate of the condenser was found to be the most sensitive parameter having influence on the cold generation capacity [13]. Thermal analysis of an activated carbon solar icemaker has been experimentally studied by Naef, Qasem, Maged and Shaarawi. The results showed that the system performance in winter is better than in summer under the climate conditions for the city Dhahran [14].

Liu and Leong have analytically investigated the influence of operating conditions on the performance of an adsorption cooling system based on the zeolite 13Xwater working pair [15]. A simple thermodynamic differential analysis for ice machine working with activated carbon-methanol has been developed by $\mathrm{H}$. $Z$. Hassan. It is found the system attains a refrigeration performance of $61 \%$ with a refrigeration effect produced inside the evaporator estimated to $12.15 \mathrm{MJ}$ per cycle [16]. A computational fluid dynamics (CFD) transient simulation of finned tube type adsorber/ desorber employing activated carbon-ethanol was analytically and experimentally studied by Skandar, Takahiko, Bidyut and Shigeru. Simulation results showed that temperature and pressure profiles agree fairly with experimental data at lower adsorbent thicknesses. Moreover, it is found that adsorption kinetics restricted the amount adsorbed to $45 \%$ of possible amount for adsorption/desorption time of $350 \mathrm{~s}$ [17].

$\mathrm{Li}$ and Wang studied theoretically and experimentally heat and mass transfer in an adsorbent bed for a flat plate solar adsorption ice-maker. $10 \mathrm{~kg}$ of methanol and $42 \mathrm{~kg}$ of activated carbon were used in a rectangular adsorbent bed of $1.5 \mathrm{~m}^{2}$ solar collector. The experimental analysis was done by constructing a device in lab and simulating the solar radiation by means of quartz lamps. The investigation showed that the numerical results from the theoretical study were in agreement with the experimental results at COP of 0.125 and 0.132 and amounts of produced ice were 8 and $7.8 \mathrm{~kg}$ for 30.24 and $29 \mathrm{MJ}$ of incident solar radiation, respectively [18].

According to working pair comparisons, for lowgrade temperature sources, the appropriate pairs for cooling purposes are activated carbon-methanol and zeolite-water [19]. However the zeolite-water pair is not utilized for freezing. So the suitable pair that can be used to produce ice is activated carbon-methanol. Methanol has a higher operation pressure compared with water under the same temperature [19]. Activated carbon is a substance of crystalline form having large internal pore structures with surfaces greater than 500 $\mathrm{m}^{2} / \mathrm{gr}$. There are many forms of activated carbon such powders, granulated, molecular sieves and carbon fibers [20]. Due to a lower specific heat capacity $\mathrm{Cp}$ and a faster sorption kinetic of the silica gel particles [10], the second sorption reactor was filled with silica gel in the AIP system. The silica gel is a type of amorphous synthetic silica. It is a rigid, continuous net of colloidal silica, connected to very small grains of hydrated $\mathrm{SiO}_{4}$. The pore diameters of common silica gel are $0.7-3 \mathrm{~nm}$ and the specific surface area is about $100-1000 \mathrm{~m}^{2} / \mathrm{gr}[21]$.

Activated carbon AC with methanol as a working pair is broadly used in adsorption refrigeration systems due to the high adsorption/desorption concentration X, which reaches $0.45\left[\mathrm{~kg}_{\text {meth }} / \mathrm{kg}_{\mathrm{AC}}\right]$ and low desorption heat, which is about $1800-2000[\mathrm{~kJ} / \mathrm{kg}]$. Moreover, adsorbate uptake capacity of activated carbon is more than that of silica gel. The other important factor is 
density of the sorption material which affects the volume of adsorption reactor. Density of activated carbon is about $500 \mathrm{~kg} / \mathrm{m}^{3}$, whereas density of silica gel is about $750 \mathrm{~kg} / \mathrm{m}^{3}$. Therefore, the needed amount of activated carbon is smaller than the amount of silica gel inside the same volume of adsorption reactor [22]. The system of activated carbon-methanol and silica gel-methanol needs low grade heat source [23, 24]. On the other hand, methanol operates at sub atmospheric pressure; the low-pressure system is suitable to utilize the adsorption cold system as ice maker [20]. In this study, the analytical investigation of the two bed-AIP system is presented. The first sorption bed is filled with silica gel-methanol as working pair and the second bed is filled with activated carbon-methanol, because of the inferior thermodynamic properties of methanol and the low regeneration temperature from silica gel and activated carbon as adsorbents.

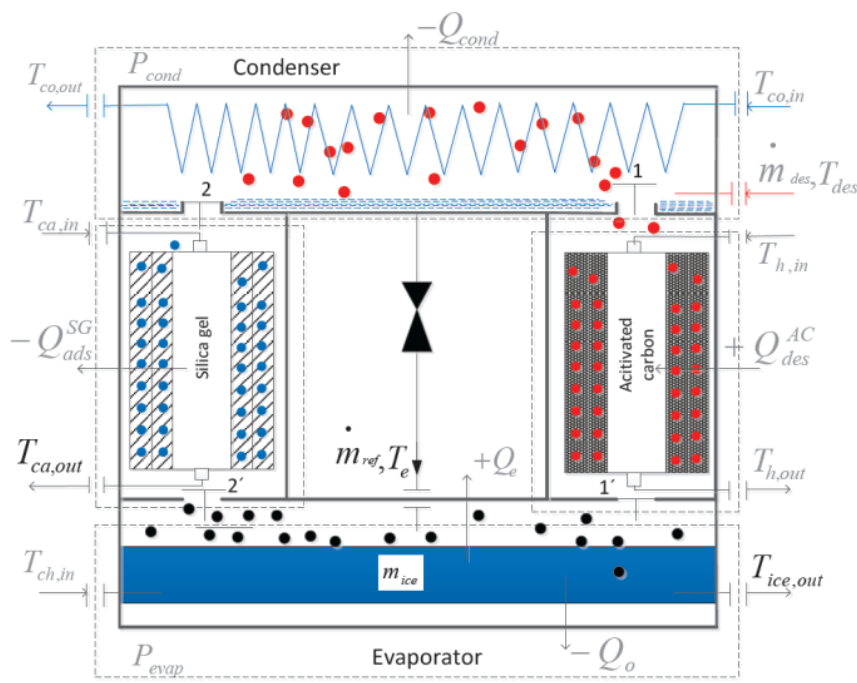

Figure 1: Schematic diagram of two- bed AIP system.

Usually the conventional adsorption systems work using one sorption material with adsorbate as working pairs, but the AIP system in this study comprises with two sorption reactors, that the first sorption reactor was filled by silica gel as adsorbent and the second sorption reactor by activated carbon. Methanol was used as adsorbate and refrigerant with both the beds. The working principle of the system will be explained in the following section.

This study allows using the advantages of physical properties of both adsorbents SG and AC. Consequently, this innovative AIP system utilizes effectively low-temperature heat sources of temperature between 65 and $100{ }^{\circ} \mathrm{C}$, because of the inferior thermodynamic properties of methanol and the low regeneration temperature from silica gel and activated carbon as

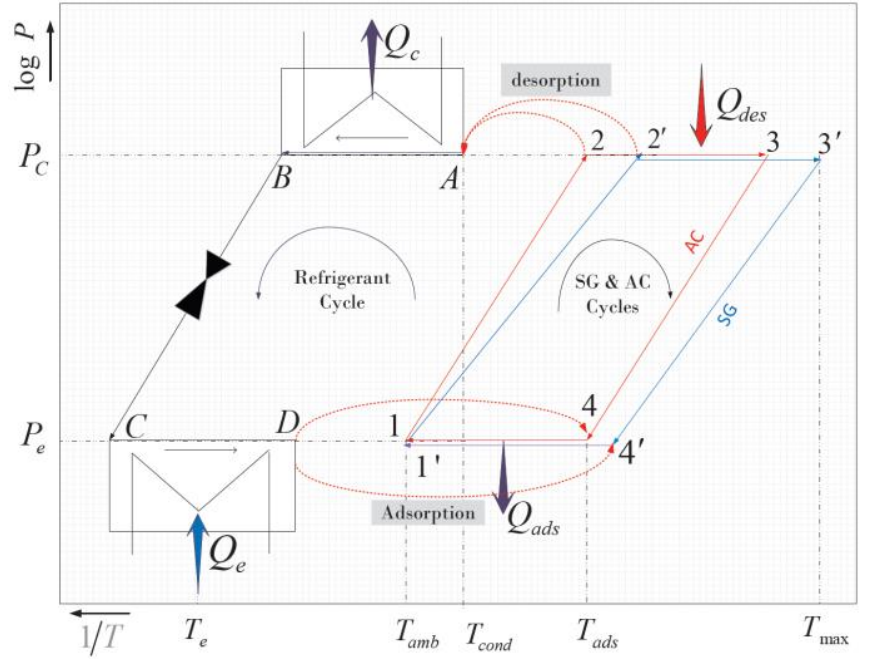

Figure 2: Clapeyron diagram for the basic Adsorption Ice Production thermodynamic cycle.

adsorbents. This strategy is completely different from the conventional adsorption reactors, which are filled with one adsorbent in one bed or in two beds. This research presents a simulation of activated carbon/silica gel-methanol finned tube adsorption cold system. Future works will focus on enhancing the specific cooling power SCP, the coefficient of performance COP and saving of the required input heat by increasing the mass flow rate of refrigerant $\dot{m}_{\text {ref }}$ from 0 to $1 \mathrm{~kg}_{\text {meth }}$ to achieve higher performance in terms of refrigeration capacity. Moreover, the impact of difference time for SC-cycle and AC- cycle and the desorption temperature inside the sorption reactor on the performance and on the amount of produced ice $m_{\text {ice }}$ are considered.

\section{THERMODYNAMIC CYCLE AND WORKING PRINCIPLE OF AIP SYSTEM}

The Adsorption Ice Production (AIP) system is similar to the basic vapor compression refrigeration machines except that the power compressor is replaced by a thermally driven compressor which is the sorption reactor [19]. The sorption reactor is composed of a solid medium that has affinity to physically adsorb and desorb the refrigerant vapor. The other main components of the system studied are a condenser, an evaporator, a throttling device and 4 one-way control valves. This components of the system studied are shown also in Figure 1.

This suggested strategy is different from the conventional adsorption reactor which works using one working pair of adsorbent/refrigerant. Its working principle will be explained in the following section. The basic adsorption refrigeration thermodynamic cycle is 
illustrated on the conceptual Clapeyron diagram, shown in Figure 2. The cycle of the AIP system consists mainly of these processes:

- $\quad 1 \rightarrow 2$ Isosteric heating and pressurization process at the constant higher concentration of methanol in the activated carbon particles in the first adsorption reactor.

- $\quad 1^{\prime} \rightarrow 2^{\prime}$ Isosteric heating and pressurization process at the constant higher concentration of methanol in the silica gel particles in the second adsorption reactor.

- $\quad 2 \rightarrow 3$ Isobaric heating and desorption process from the activated carbon particles.

- $\quad 2^{\prime} \rightarrow 3^{\prime}$ Isobaric heating and desorption process from the silica gel particles.

- $\quad 3 \rightarrow 4$ Isosteric cooling and depressurization process at the constant lower concentration of methanol in the activated carbon adsorbent.

- $\quad 3^{\prime} \rightarrow 4^{\prime}$ Isosteric cooling and depressurization process at the constant lower concentration of methanol in the silica gel particles.

- $\quad 4 \rightarrow 1$ Isobaric cooling and adsorption process for the AC-adsorbent.

- $\quad 4 \rightarrow 1$ Isobaric cooling and adsorption process for the SG-adsorbent.

- $\quad \mathrm{A} \rightarrow \mathrm{B}$ condensation process at constant condenser pressure.

- $\quad \mathrm{C} \rightarrow \mathrm{D}$ evaporation process at constant evaporator pressure.

At the beginning of the cycle for AC-sorption reactor, state 1, the AC-sorption reactor is isolated from both the condenser and the evaporator by the valves $V_{1}$ and $V_{16}$ and the AC-bed with the sorption material of activated carbon is completely charged and saturated with the refrigerant (methanol). The pressure inside the heat exchanger initially equals the evaporator pressure $P_{\text {evap }}$ and its temperature is uniform and equals the ambient temperature $T_{\text {amb. }}$. When the hot water flows into the AC-bed, both pressure and temperature inside the heat exchanger are elevated due to the adsorbate (methanol) desorption from the adsorbent particles.

During the step $1 \rightarrow 2$, the $A C$-heat exchanger through an isosteric pre-heating process absorbs heat in amount of $Q_{112 t}^{A C}$ from an external heat source. During the step $1^{\prime} \rightarrow 2^{\prime}$, the SG- heat exchanger through an isosteric pre-heating process also absorbs heat in amount of $Q_{12}^{S C}$ from the same external heat source. The constant concentration preheating process continues until the pressure of $\mathrm{AC}$-adsorbent bed and SG- adsorption bed reach the pressure of condenser $P_{\text {cond. }}$.

At the time, the entrance valves $V_{1}$ and $V_{2}$ to the condenser are opened. In the next step the external heat source continuously heats the SG-sorption reactor and $\mathrm{AC}$ - sorption reactor during an isobaric desorption process $2 \rightarrow 3$ for AC- cycle and $2^{\prime} \rightarrow 3^{\prime}$ for SG- cycle. In this process the adsorbate (methanol) leaves the sorption reactor and is condensed inside the condenser at isobaric cooling process $A \rightarrow B$. In this time, the valves $V_{1}$ and $V_{2}$ between the sorption reactor and condenser are closed in order to disconnect the sorption reactor from the condenser and start the bed pre-cooling process. In the condenser the refrigerant vapor losses both sensible heat and latent heat.

In parallel with the desorption process, the sorption reactor is still being heated and the pressure inside the bed is fixed at the condenser pressure. The temperature continues to increase until the desorption temperature $\mathrm{T}_{\max }$. The adsorbate content inside the SG- and AC-particles continues to decrease as more adsorbate is being freed from the SG-reactor and ACreactor. This operation continues for a certain period of time until no more adsorbate can be generated from the bed and the reactor temperature reaches the heat source temperature [16].

During an isosteric pre-cooling process $3 \rightarrow 4$, the AC adsorbent loses its heat $Q_{23}^{A C}$ in contact with a heat sink and the SG-adsorbent loses its heat $Q_{2 t 3 i}^{S G}$ during the process $3^{\prime} \rightarrow 4^{\prime}$. In the step $B \rightarrow C$ the refrigerant (methanol from the SG and $A C$ particles) passes through the expansion valve and enters to the evaporator. During step $C \rightarrow D$ the refrigerant absorbs heat in amount of Qevap from the environment of interest converts to the vapor. At the same time, the entrance valves $V_{11}$ to the $\mathrm{AC}$-adsorption reactor and $V_{2 t}$ to the SG-sorption reactor are opened and the adsorbents (silica gel and activated carbon) adsorb the vapor refrigerant (methanol) during an isobaric adsorption processe $4^{\prime} \rightarrow 1^{\prime}$ and $4 \rightarrow 1$ respectively. During an isobaric adsorption process release the SGsorption reactor and $\mathrm{AC}$-sorption reactor the heat $Q_{a d s}^{S G}, Q_{a d s}^{A C}$. The reactor is being cooled during this period in order to remove the generated heat from the exothermic adsorption. The evaporation-adsorption process takes place at the constant evaporator pressure. 


\section{GEOMETRY MODEL PARAMETERS OF FINNED TUBE FOR THE SORPTION REACTOR}

Figure 3 shows the schematic view of the finned tube heat exchanger developed in this study. It mainly consists of:

1. Tubes of copper having inner diameter $17.3 \mathrm{~mm}$ and length $450 \mathrm{~mm}$;

2. Fins of aluminum characterized by fin height $\mathrm{H}_{\mathrm{f}}=40 \mathrm{~cm}$, fin thickness $\mathrm{s}=1 \mathrm{~mm}$ and fin pitch $\mathrm{t}_{\mathrm{f}}=4$ $\mathrm{mm}$;

3. Mesh sheet covering the material of the heat exchanger.

This heat exchanger is composed of flat tube with rectangular fins. To desorb/adsorb $1 \mathrm{~kg}_{\text {meth }}$ of circulated refrigerant mass from the SG-sorption reactor, there are 4 tubes horizontally and 90 fins vertically arranged adsorption heat exchanger in all, between $7.9 \mathrm{~kg}$ silica gel and $1.9 \mathrm{~kg}$ methanol are employed. To desorb also the same masse of circulated refrigerant, there are 2 tubes horizontally and 90 fins vertically arranged adsorption heat exchanger in all, between $3.31 \mathrm{~kg}$ activated carbon and $1.36 \mathrm{~kg}$ methanol are employed. Silica gel and activated carbon particles are taken as same diameter $(f 1.15 \mathrm{~mm})$. This heat exchanger is used as desorber during desorption cycles and as an adsorber during adsorption cycles. The characteristics of the fined -tube heat exchanger used in SG sorption reactor and in AC-sorption reactor have been calculated and listed in the Table 1.

\section{MATHEMATICAL FORMULATION}

\subsection{Adsorption and Desorption Equations}

The concentration ratio of the refrigerant $X[\mathrm{~kg} / \mathrm{kg}]$ by the adsorbent particles depends upon the pressure and the temperature of the adsorbate. The maximum value $X_{\max }$ is defined by the ambient temperature and evaporator pressure $X_{\max }=f\left(T_{a m b}, P_{\text {evap }}\right)$. The

Table 1: Characteristics of the Fined-Tube Combined Heat Exchanger

\begin{tabular}{|c|c|c|c|}
\hline Parameter & SG- heat exchanger & AC- heat exchanger & Unit \\
\hline Dimension & $4500^{\prime} 1500^{\prime} 400$ & $4500^{\prime} 1500^{\prime} 200$ & {$[\mathrm{~mm}]$} \\
\hline Number of flat tube & 4 & 2 & {$[-]$} \\
\hline Tube diameter & 17.3 & 17.3 & {$[\mathrm{~mm}]$} \\
\hline Tube thickness $(x)$ & 0.8 & 0.8 & [mm] \\
\hline Number of fins & 90 & 90 & {$[-]$} \\
\hline Fin width $\left(B_{f}\right)$ & 150 & 150 & {$[\mathrm{~mm}]$} \\
\hline Fin pitch $\left(t_{f}\right)$ & 4 & 4 & {$[\mathrm{~mm}]$} \\
\hline Heat transfer area $(A)$ & 10.68 & 5.34 & {$\left[\mathrm{~m}^{2}\right]$} \\
\hline Emptied volume (V) & 0.0212 & 0.0106 & {$\left[\mathrm{~m}^{3}\right]$} \\
\hline
\end{tabular}
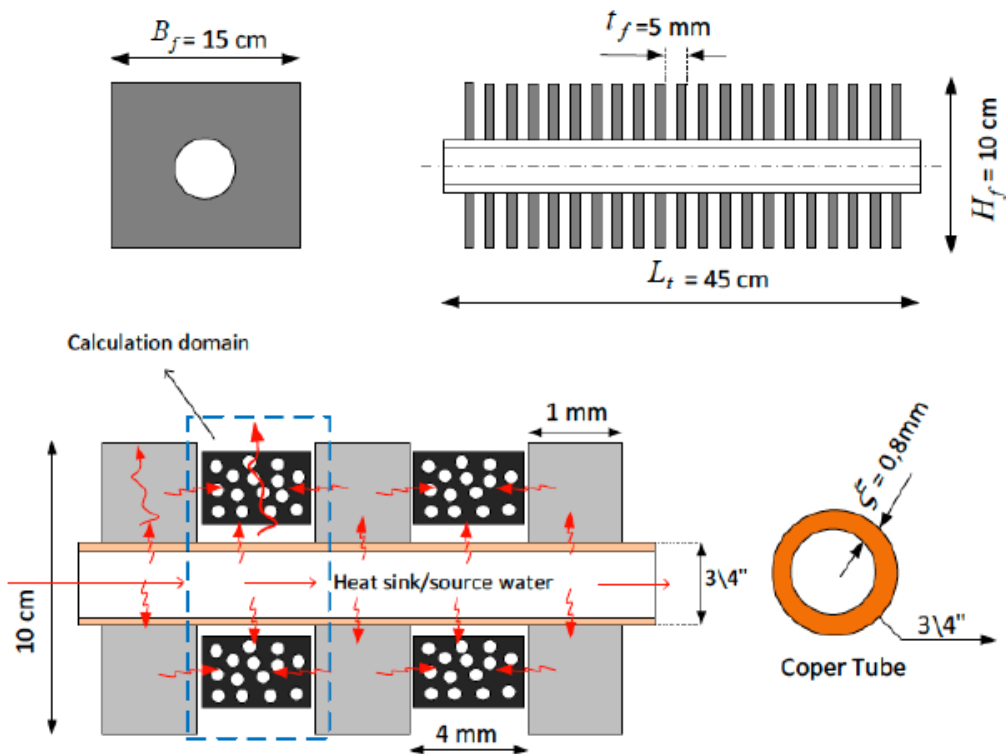

Coper Tube

Figure 3: Schematic diagram for the one rectangular finned tube sorption reactor of the AIP system. 
concentrations $\mathrm{X}$ during the adsorption and desorption processes are usually determined by Dubinin-Astakhov equation $[20,21]$ :

$\mathrm{X}_{(\mathrm{T}, \mathrm{P})}=\mathrm{X}_{0} \exp \left\{-\mathrm{D} \cdot\left[\mathrm{T} \cdot \ln \left(\frac{\mathrm{P}_{\text {sat }}}{\mathrm{P}}\right)\right]^{\mathrm{n}}\right\}$

The initial adsorption concentration $\mathrm{X}_{0}$ depends on the adsorbate density $r_{a}(T)$ and is related to the maximum adsorption capacity by this equation:

$X_{0}=r_{a}(T) \cdot V_{0}$

where $V_{0}\left[\mathrm{~m}^{3} / \mathrm{kg}\right]$ is the maximum adsorption capacity. $\mathrm{D}$ and $\mathrm{n}$ are constants which can be determined experimentally in depending on the adsorbate/ adsorbent pair [22]. $\mathrm{P}_{\text {sat }}(\mathrm{T})$ is saturation pressure and temperature corresponding to the sorption reactor temperature.

The relation between the pressure and temperature during the isosteric pre-heating and pre-cooling processes at steady state conditions is described by following equations:

$\mathrm{P}=\mathrm{P}_{\mathrm{sat}}(\mathrm{T}) \cdot \exp \left\{\frac{-1}{\mathrm{~T}}\left[\frac{1}{\mathrm{D}} \ln \left(\frac{\mathrm{x}_{0}}{\mathrm{x}}\right)\right]^{1 / \mathrm{n}}\right\}$

For a given evaporator temperature $\mathrm{T}_{\text {evap, }}$ the corresponding evaporator pressure, $P_{\text {evap }}$ is the saturation pressure of the refrigerant vapor $\mathrm{P}_{\text {sat }}\left(T_{\text {evap }}\right)$ $=P_{\text {evap }}$ corresponding to $T_{\text {evap }}$.

According to equations (3) the processes cycle of AIP system can be displayed very well in (P-T) diagram (Figure 2). In this diagram the processes are plotted as two trapeziums. The first trapezium for SG-bed is plotted between the isosteres $X_{\max }^{S G}$ and $X_{\min }^{S G}$ and the isobares $\mathrm{P}_{\text {cond }}$ and $\mathrm{P}_{\text {evap. }}$. Another trapezium for AC-bed is too plotted at the same diagram with different values of $X_{\max }^{A C}$ and $X_{\min }^{A C}$ and with same evaporator and condenser pressure.

The kinetics of sorption $d X / d t$ is assumed to be governed by a linear driving force (LDF) model that could be used to describe internal mass transfer limitations with little error [22-24]. The term of the model is given by:

$\frac{d X}{d t}=D_{s o} \cdot\left(X_{e q}-X\right)$

Where $X_{\text {eq }}$ is the equilibrium concentration at the corresponding pressure and temperature that is calculated by Dubinin-Astakhov Eq. (1) and X represents the actual concentration of the adsorbate. The overall mass transfer coefficient $D_{\text {so }}$ for adsorption/desorption is given by:
$\mathrm{D}_{\mathrm{so}}=\frac{11 \cdot \mathrm{D}_{\mathrm{o}}}{r_{P}^{2}} \cdot e^{(-E a / R \cdot T)}$

\subsection{Isosteric Heating and Isobaric Desorption Processes}

In the isosteric heating process, the methanol concentration in the heat exchanger remains constant. The added energy $Q_{\text {heat }}^{s}$ during this process of the sorption reactor is utilized to cause sensible heating of the sorption reactor constituents. During isobaric desorption process the methanol concentration by sorption material decreases by increasing desorption temperature from the maximum value $X_{\max }^{S}\left(P_{\text {cond }}, T_{\text {cond }}\right)$ to the minimum value $X_{\min }^{S}\left(P_{\text {cond }}, T_{b}\right)$. The variation of the adsorbate concentration ratio along the isobaric desorption process is defined by the Eq. 1 .

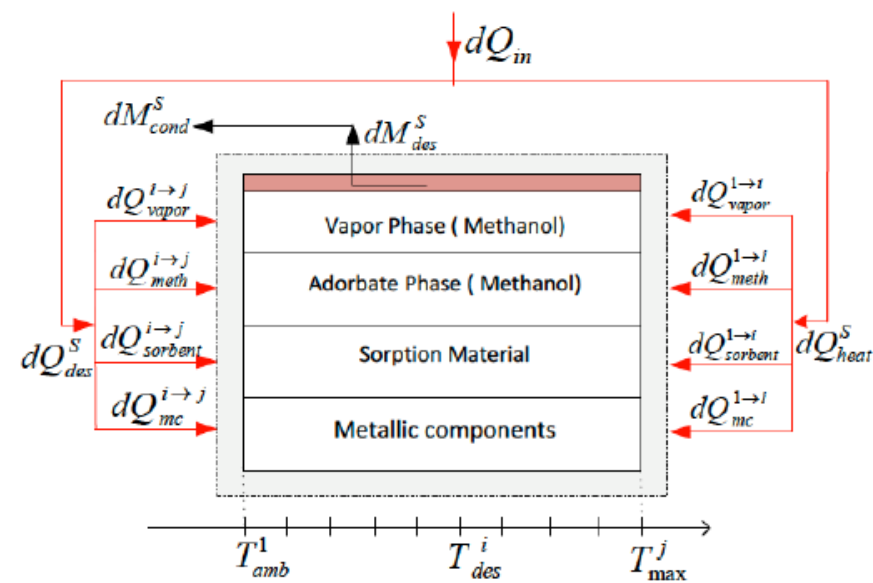

Figure 4: Energy flow diagram for the desorption reactor during the isosteric and isobaric heating processes.

The amount of the added energy $Q_{\text {des }}^{S}$ which is required during the isobaric desorption process causes also sensible heating of the sorption reactor constituents, activates desorption of the refrigerant from the adsorbent media (SG, AC) and generates the gas phase.

The summation of the isosteric heat together the desorption heat is called the input energy required form the external heat source for generation the sorption reactor and is given as:

$$
\begin{aligned}
& Q_{\text {in }}=\int_{1}^{\mathrm{i}} \mathrm{dQ}_{\text {heat }}+\int_{\mathrm{i}}^{\mathrm{j}} \mathrm{dQ}_{\mathrm{des}} \\
& \mathrm{Q}_{\mathrm{in}}=\int_{1}^{i}\left[\mathrm{dQ}_{\mathrm{mc}}^{\mathrm{s}}+\right.\left.d Q_{\text {sorbent }}^{\mathrm{s}}+\mathrm{dQ}_{\text {adsorbat }}^{\mathrm{s}}+\mathrm{dQ}_{\text {vapor }}^{\mathrm{s}}\right] \\
&+\int_{i}^{j}\left[\mathrm{dQ}_{\mathrm{mc}}^{\mathrm{S}}+\mathrm{dQ}_{\text {sorbent }}^{\mathrm{s}}+\mathrm{dQ}_{\text {adsorbat }}^{\mathrm{s}}\right. \\
&\left.+\mathrm{d} Q_{\text {vapor }}^{\mathrm{S}}\right]
\end{aligned}
$$




$$
\begin{aligned}
& \mathrm{Q}_{\text {in }}=\int_{1}^{i}\left[\mathrm{dQ}_{\mathrm{mc}}^{\mathrm{s}}+\mathrm{dQ}_{\text {sorbent }}^{\mathrm{s}}+\mathrm{dQ}_{\text {adsorbat }}^{\mathrm{s}}+\mathrm{dQ}_{\text {vapor }}^{\mathrm{s}}\right] \\
& +\int_{i}^{j}\left[\mathrm{dQ}_{\mathrm{mc}}^{\mathrm{s}}+\mathrm{dQ}_{\text {sorbent }}^{\mathrm{s}}+\mathrm{dQ}_{\text {adsorbat }}^{\mathrm{s}}\right. \\
& \left.+\mathrm{dQ}_{\text {vapor }}^{\mathrm{S}}\right] \\
& \mathrm{Q}_{\mathrm{in}}=\int_{1}^{j}\left[\mathrm{dQ}_{\mathrm{mc}}^{\mathrm{S}}+\mathrm{dQ}_{\text {sorbent }}^{\mathrm{S}}\right]+\int_{1}^{i}\left[\mathrm{dQ}_{\text {adsorbat }}^{\mathrm{s}}+\mathrm{dQ}_{\text {vapor }}^{\mathrm{S}}\right] \\
& +\int_{i}^{j}\left[\mathrm{dQ}_{\text {adsorbat }}^{\mathrm{s}}+\mathrm{dQ} \text { vapor }\right] \\
& \mathrm{Q}_{\mathrm{in}}=\int_{1}^{j}\left[\mathrm{dQ}_{\mathrm{mc}}^{\mathrm{S}}+\mathrm{dQ}_{\text {sorbent }}^{\mathrm{S}}\right]+\int_{1}^{i}\left[\mathrm{dQ}_{\text {adsorbat }}^{\mathrm{S}}+\mathrm{dQ}_{\text {vapor }}^{\mathrm{S}}\right] \\
& +\int_{i}^{j}\left[\mathrm{dQ}_{\text {adsorbat }}^{\mathrm{s}}+\mathrm{dQ}_{\mathrm{vapor}}^{\mathrm{s}}\right] \\
& Q_{\text {in }}=\int_{1}^{j}\left(M_{t, c u} \cdot C_{P, C u}+M_{f, A l} \cdot C_{P, A l}+M_{S} \cdot C_{P, s}\right) \cdot d T \\
& +\int_{1}^{\mathrm{i}}\left(\mathrm{X}_{\max }^{\mathrm{S}} \cdot \mathrm{M}_{\mathrm{S}} \cdot \mathrm{C}_{\mathrm{V}, \mathrm{a}}+\mathrm{M}_{\mathrm{v}} \cdot \mathrm{C}_{\mathrm{V}, \mathrm{v}}\right) \cdot \mathrm{dT} \\
& +\int_{i}^{j} M_{S} \cdot\left[C_{P, a} d(X . T)+d\left(X . h_{v}\right)\right] \\
& Q_{\text {in }}=\int_{1}^{j}\left(M_{t, c u} \cdot C_{p, C u}+M_{f, A l} \cdot C_{P, A l}+M_{S} \cdot C_{p, s}\right) \cdot d T \\
& +\int_{1}^{i}\left(X_{\max }^{S} \cdot M_{S} \cdot C_{V, a}+M_{v} \cdot C_{V, v}\right) \cdot d T \\
& +\int_{i}^{j} M_{S} \cdot\left[C_{P, a} d(X . T)+d\left(X \cdot h_{v}\right)\right]
\end{aligned}
$$

Where $S$ indicates the SG adsorbent or the $A C$ adsorbent depending whether the sorption reactor is working as adsorber or desorber. The flag $i=2$ and $j=3$ in case the AC-bed is working as desorber, whereas $i=2 t$ and $j=3 t$ in case the SG-bed is working as desorber.

\subsection{Isosteric Cooling and Isobaric Adsorption Processes}

Using the same methodology which has been followed in the last section, the energy which is removed from the sorption reactor to the ambient heat sink at $T_{a m b}$ is in a sensible form during isosteric cooling process $Q_{\text {cool }}^{S}$ and consists of the reactor cooling energy in addition to the adsorption energy during the isobaric cooling process $Q_{a d s}^{S}$.

The total amount of energy removed from the reactor during isosteric and isobaric cooling is called the output energy $Q_{\text {out }}$ and is given as follows:

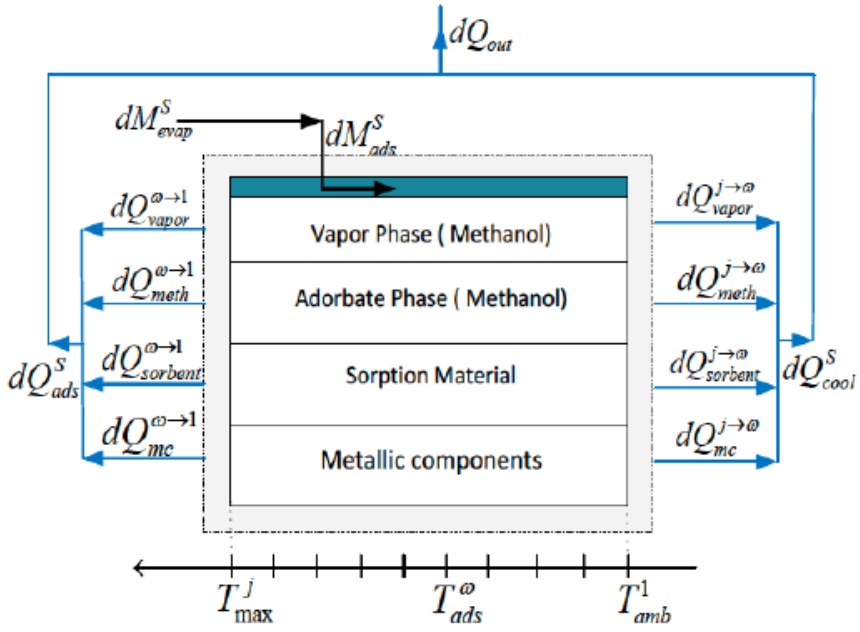

Figure 5: Energy flow diagram for the adsorption reactor during the isosteric and isobaric cooling processes.

$$
\begin{aligned}
& \mathrm{Q}_{\text {out }}=\int_{j}^{\omega} \mathrm{dQ}_{\mathrm{cool}}+\int_{\omega}^{1} \mathrm{dQ}_{\mathrm{ads}} \\
& \mathrm{Q}_{\text {out }}=\int_{j}^{\omega}\left[\mathrm{dQ}_{\mathrm{mc}}^{\mathrm{s}}+\mathrm{dQ}_{\text {sorbent }}^{\mathrm{s}}+\mathrm{dQ}_{\text {adsorbat }}^{\mathrm{s}}+\mathrm{dQ}_{\text {vapor }}^{\mathrm{S}}\right] \\
& +\int_{\omega}^{1}\left[\mathrm{dQ}_{\mathrm{mc}}^{\mathrm{S}}+\mathrm{dQ}_{\text {sorbent }}^{\mathrm{s}}+\mathrm{dQ}_{\text {adsorbat }}^{\mathrm{s}}\right. \\
& \left.+\mathrm{dQ}_{\text {vapor }}^{\mathrm{S}}\right] \\
& \mathrm{Q}_{\text {out }}=\int_{j}^{\omega}\left[\mathrm{dQ}_{\mathrm{mc}}^{\mathrm{s}}+\mathrm{dQ}_{\text {sorbent }}^{\mathrm{s}}+\mathrm{dQ}_{\text {adsorbat }}^{\mathrm{s}}+\mathrm{dQ}_{\mathrm{vapor}}^{\mathrm{s}}\right]+ \\
& \int_{\omega}^{1}\left[\mathrm{~d}_{\mathrm{mc}}^{\mathrm{S}}+\mathrm{d}_{\text {sorbent }}^{\mathrm{s}}+\mathrm{dQ}_{\text {adsorbat }}^{\mathrm{S}}+\mathrm{dQ}_{\text {vapor }}^{\mathrm{S}}\right] \\
& \begin{aligned}
Q_{\text {out }}=\int_{j}^{1}\left[\mathrm{dQ}_{\mathrm{mc}}^{\mathrm{S}}\right. & \left.+\mathrm{d} \mathrm{Q}_{\text {sorbent }}^{\mathrm{S}}\right]+\int_{j}^{\omega}\left[\mathrm{d} \mathrm{Q}_{\text {adsorbat }}^{\mathrm{S}}+\mathrm{d} \mathrm{Q}_{\text {vapor }}^{\mathrm{S}}\right] \\
& +\int_{\omega}^{1}\left[\mathrm{~d} \mathrm{Q}_{\text {adsorbat }}^{\mathrm{S}}+\mathrm{dQ}_{\text {vapor }}^{\mathrm{S}}\right]
\end{aligned}
\end{aligned}
$$$$
\mathrm{Q}_{\text {out }}=\int_{j}^{1}\left[\mathrm{dQ}_{\mathrm{mc}}^{\mathrm{S}}+\mathrm{d} \mathrm{Q}_{\text {sorbent }}^{\mathrm{s}}\right]+\int_{j}^{\omega}\left[\mathrm{d} \mathrm{Q}_{\text {adsorbat }}^{\mathrm{S}}+\mathrm{d} \mathrm{Q}_{\mathrm{vapor}}^{\mathrm{S}}\right]
$$$$
+\int_{\omega}^{1}\left[\mathrm{dQ}_{\text {adsorbat }}^{\mathrm{s}}+\mathrm{dQ} \mathrm{V}_{\text {vapor }}^{\mathrm{s}}\right]
$$$$
Q_{\text {out }}=\int_{j}^{1}\left(M_{t, c u} \cdot C_{P, C u}+M_{f, A l} \cdot C_{P, A l}+M_{s} \cdot C_{P, s}\right) \cdot d T
$$$$
+\int_{\dot{j}}^{\omega}\left(X_{\min }^{s} \cdot M_{S} \cdot C_{V, a}+M_{v} \cdot C_{V, v}\right) \cdot d T
$$$$
+\int_{\omega}^{1} M_{S} \cdot\left[C_{P, a} d(X . T)+d\left(X . h_{v}\right)\right]
$$

$$
\begin{aligned}
& Q_{\text {out }}=\int_{j}^{1}\left(M_{t, c u} \cdot C_{P, C u}+M_{f, A l} \cdot C_{P, A l}+M_{S} \cdot C_{P, s}\right) \cdot d T \\
&+\int_{j}^{\omega}\left(X_{\min }^{S} \cdot M_{S} \cdot C_{V, a}+M_{v} \cdot C_{V, v}\right) \cdot d T \\
&+\int_{\omega}^{1} M_{S} \cdot\left[C_{P, a} d(X \cdot T)+d\left(X \cdot h_{v}\right)\right]
\end{aligned}
$$


Where the flag $w=4$ in case the AC-bed is working as adsorber, whereas $w=4 t$ in case the SG-bed is working as adsorber.

\subsection{Coefficient of Performance (COP)}

To evaluate the efficiency of the sorption cooling cycles, the coefficient of performance COP is used. In AIP system, the COP is defined as the ratio of evaporative refrigeration energy $Q_{e}$ to the amount of input energy required form an external heat source $Q_{\text {in. }}$ The evaporative refrigeration energy produced in the evaporator can be calculated from:

$\mathrm{Q}_{\mathrm{e}}=\int\left[(1-\mathrm{z}) \cdot \mathrm{L}_{\mathrm{e}}+\left(\mathrm{h}_{\text {evap }}(\mathrm{T})-\mathrm{h}_{\text {sat }}\left(\mathrm{P}_{\text {evap }}\right)\right)\right] \cdot \delta \mathrm{M}_{\text {evap }}$

where $a M_{\text {evap }}$ is the differential desorbed mass of methanol vapour that leaves the evaporator and enters the adsorption reactor and equals the total refrigerant mass content inside the SG adsorbent or the AC adsorbent. This infinitesimal amount of mass can be written, taking into account the mass of adsorbate vapor $a M_{v}$, as follows:

$$
\begin{aligned}
& \delta \mathrm{M}_{\text {evap }}=\delta \mathrm{M}_{\mathrm{ads}}=\left[\delta \mathrm{M}_{\mathrm{a}}+\delta \mathrm{M}_{\mathrm{v}}\right]_{\mathrm{ads}}^{\mathrm{s}} \\
& \delta \mathrm{M}_{\text {evap }}=\left[\mathrm{M}_{\mathrm{a}} \cdot \delta \mathrm{X}+\rho_{\mathrm{v}} \cdot\left(\beta-\frac{(1-\beta) \cdot \rho_{s}}{\rho_{a}} \cdot \delta \mathrm{X} \cdot\right) \cdot \mathrm{v}\right]_{\mathrm{ads}}^{\mathrm{s}}
\end{aligned}
$$

The cold adsorption system is used for freezing applications; the total amount of the ice produced from the AIP system per cycle is given by;

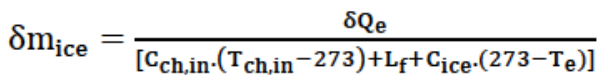

\subsection{Specific Cooling Power (SCP)}

It is defined as the ratio of evaporative refrigeration energy to the mass of dry sorption material multiplied by the cycle time. The SCP represents the amount of refrigeration power produced per unit mass of dry adsorbent, Eq.12.

$$
\mathrm{SCP}=\frac{\mathrm{Q}_{\mathrm{e}}}{\mathrm{M}_{\mathrm{s}} \cdot \mathrm{t}_{\mathrm{cycle}}}
$$

\subsection{Efficiency of the Refrigeration Utilization $\mu_{\mathrm{m}}^{\mathrm{S}}$}

In the present study the circulated refrigerant mass through the system is taken as constant value of $1 \mathrm{~kg}$ in the simulation. In order to assess the effectiveness of refrigeration mass utilization on the AIP system the efficiency of refrigeration mass utilization $m_{m}^{S}$ is used. This parameter is defined as the ratio between the circulated refrigerant mass to the total refrigerant mass which is correspond to maximum value of adsorbate uptake and required to charge each the bed to desorb/adsorb $1 \mathrm{~kg}$. The ${ }_{m}^{S}$ is given by;

$$
\mu_{m}^{s}=\frac{M_{r e f}^{S}}{M_{S} \cdot\left(X_{\max }^{S}-X_{\min }^{S}\right)}
$$

\section{CALCULATION PROCEDURE}

The analysis of the Adsorption Ice Maker AIP system with two-heat exchanger has been investigated using a simulation program written in Matlab. This program is designed to analyze the thermodynamic cycle parameters of this technique. The above mentioned set of coupled equations is solved by finite difference approximation with a temperature step of one grad Celsius and with a time step of one second. The investigation focused on the effect of the difference time of desorption and adsorption processes for SG and $\mathrm{AC}$ as adsorbents, the sorption reactor temperature $T_{b}$, the thermal performance (coefficient of performance COP and specific cooling power SCP) and the amount of produced ice mice.

Table 2: The Characteristics of Maxsorb Activated Carbon and Silica Gel Used in this Study. (Data Reported by Kanasi Coke and Chemical, Japan)

\begin{tabular}{|c|c|c|}
\hline Parameter & Activated Carbon & Silica Gel \\
\hline \hline Absolute Density $\boldsymbol{\rho}_{\mathbf{s}}$ & $400-600\left[\mathrm{~kg} / \mathrm{m}^{3}\right]$ & $700-750\left[\mathrm{~kg} / \mathrm{m}^{3}\right]$ \\
\hline BET Surface Area & $2250\left[\mathrm{~m}^{2} / \mathrm{gr}\right]$ & $800\left[\mathrm{~m}^{2} / \mathrm{gr}\right]$ \\
\hline Specific Heat Capacity $\mathbf{C}_{\mathbf{p}}$ & $0.93[\mathrm{~kJ} / \mathrm{kg} \cdot \mathrm{K}]$ & $0.85[\mathrm{~kJ} / \mathrm{kg} \cdot \mathrm{K}]$ \\
\hline Porosity $\boldsymbol{\beta}$ & 0.858 & 0.5 \\
\hline $\mathrm{X}_{0}$ & $1.24 \mathrm{~kg}_{\mathrm{m}} / \mathrm{kg}_{\mathrm{ac}}$ & $0.35 \mathrm{~kg}_{\mathrm{m}} / \mathrm{kg}_{\mathrm{ac}}$ \\
\hline $\mathrm{n}$ & 2,0 & 1,7 \\
\hline $\mathrm{D}$ & $4.022-10^{-6}$ & $9.08-10^{-6}$ \\
\hline $\mathrm{E}_{\mathrm{a}}$ & $306.766[\mathrm{~kJ} / \mathrm{kg}]$ & $1310.76[\mathrm{~kJ} / \mathrm{kg}]$ \\
\hline
\end{tabular}


The case investigated in the present study is an ice maker at an evaporation temperature of $-3^{\circ} \mathrm{C}$. The new strategy operates with both silica gel/methanol as a working pair in the SG-bed and operates with activated carbon/methanol as a working pair in the AC-bed of AIP system. The characteristics of activated carbon and silica gel, used in the studied system, are shown in Table 2. To adsorb or desorb the same amount of the circulated refrigerant through the AIP system in case the AC-bed is working or the SG-bed is working, the analysis of the cooling processes and adsorption/ desorption processes for two sorption reactor theoretical were simulated by using $3.31 \mathrm{~kg}$ of activated carbon, $1.36 \mathrm{~kg}$ of methanol in the AC-sorption reactor of $2.67 \mathrm{~m}^{2}$ heat transfer area and by using $7.95 \mathrm{~kg}$ of silica gel, $1.9 \mathrm{~kg}$ of methanol in the SG-sorption reactor of $5.34 \mathrm{~m}^{2}$ heat transfer area. Therefore the configuration of these sorption elements isn't identical. In the proposed design the effect of metallic casing of the com- adsorption bed is taken into account.

Table 3: The Base Parameters Used in this Case Study

\begin{tabular}{|c|c|c|c|}
\hline Parameter & Value & Parameter & Value \\
\hline \hline $\mathrm{T}_{\text {evap }}$ & $-3{ }^{\circ} \mathrm{C}$ & $\mathrm{T}_{\text {amb }}$ & $27^{\circ} \mathrm{C}$ \\
\hline $\mathrm{T}_{\text {cond }}$ & $32{ }^{\circ} \mathrm{C}$ & $\mathrm{T}_{\max }$ & $100{ }^{\circ} \mathrm{C}$ \\
\hline $\mathrm{P}_{\text {evap }}$ & $3.3[\mathrm{kPa}]$ & $\mathrm{P}_{\text {cond }}$ & $24[\mathrm{kPa}]$ \\
\hline
\end{tabular}

The base parameters used in this case study are summarized in Table 3 . The liquid and vapor thermodynamic properties of methanol have been calculated from the methanol equations [25]. The simulation uses embedded Refprop thermo physical properties of methanol.

\section{RESULTS AND DISCUSSION}

\subsection{Pressure Profile}

The pressure of both the SG-bed and AC-bed rises from the evaporator pressure at $3.31 \mathrm{kPa}$ corresponding to evaporation temperature $-3{ }^{\circ} \mathrm{C}$ to the highest cycle pressure at the condenser of $24 \mathrm{kPa}$ corresponding to condensation temperature $32{ }^{\circ} \mathrm{C}$. In Figure 6 the various modes of the AIP system are designated by numbers: $1 t, 2 t, 3 t, 4 t$ cycle processes of SG-adsorbent bed and 1, 2, 3, 4 cycle processes of AC-adsorbent bed. The result corresponds to the ideal cycle displayed in Figure 2 based to the Eq. 3 . Although each of adsorbent bed was filled by different sorption material, we can notice the pressure variation inside the SG-bed and AC-bed related to the temperature remains identical;

The pressure variation of one complete cycle with time inside the SG-adsorbent bed and AC-adsorbent bed have also been studied and demonstrated in Figure 7. During the adsorption process the pressure in the SG-and AC-bed is set with regard to the evaporation pressure of methanol in the evaporator $\mathrm{P}_{\text {evap }\left(\mathrm{T}_{\text {exp }}=3^{\circ} \mathrm{C}\right)}=3.31 \mathrm{kPa}$, which gives the lower limit. During the desorption process the pressure in the SGand AC-bed is set with regard to the condensation pressure in the condenser $P_{\text {cond }\left(T_{\text {cond }}=32^{\circ} \mathrm{C}\right)}=24 \mathrm{kPa}$, which gives the upper limit. By the isosteric heating and cooling the pressure changes by variation the temperature in the heat exchangers of the AIP system.
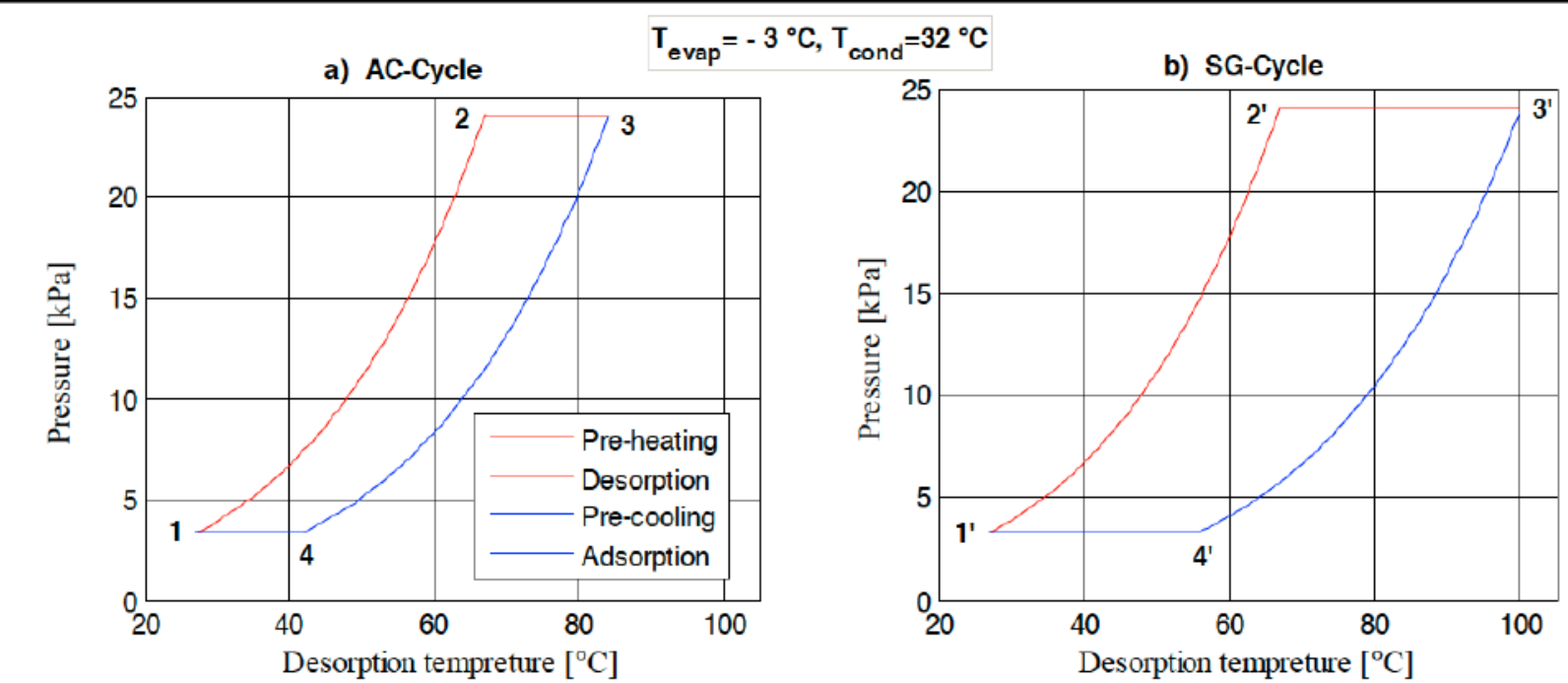

Figure 6: Variation of the sorption reactor pressure versus the temperature along the cycle processes for; (a) AC-bed and (b) SG-bed. 


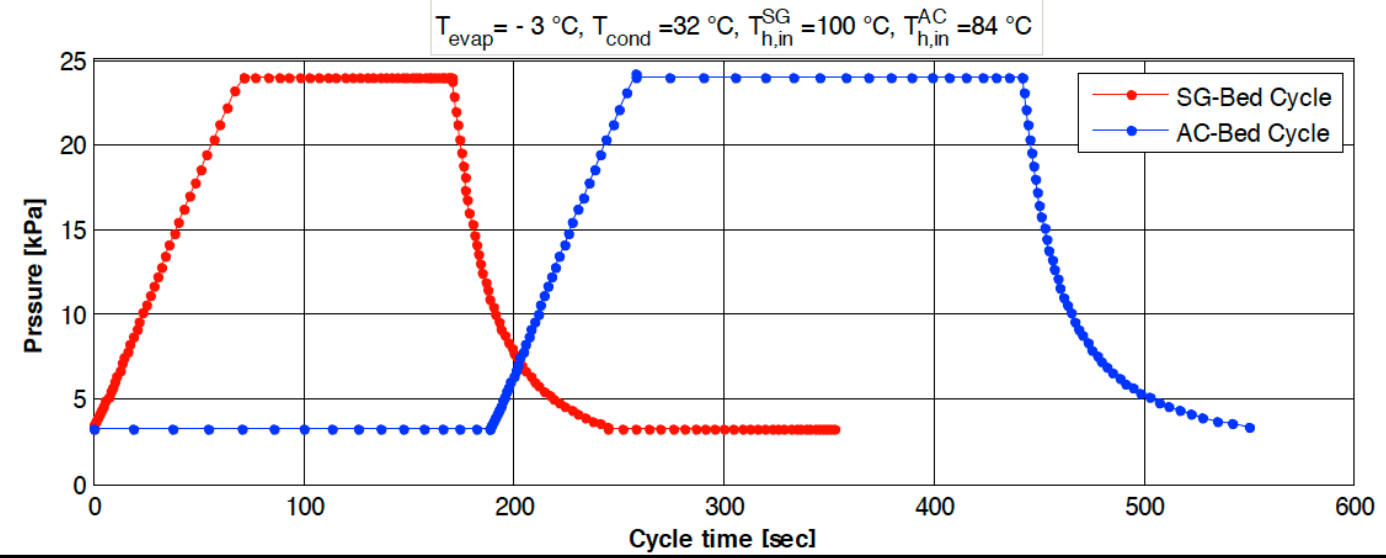

Figure 7: Variation of the SG-/AC- sorption reactor pressure along the cycle time.

In Figure 7 the cycle processes of SG-sorption reactor and $\mathrm{AC}$-sorption reactor are displayed. Both the adsorption and desorption processes of SG-cycle take about $100 \mathrm{sec}$, whereas adsorption and desorption processes of AC-cycle are completed in about $185 \mathrm{sec}$. Consequently; both of the adsorbents work under the same pressures but with the different time.

\subsection{Adsorption Uptake Profile}

Because the equilibrium adsorbate concentration of silica gel is rather low and usually doesn't exceed 0.24 $[\mathrm{kg} / \mathrm{kg}]$, the second sorption reactor was filled by activated carbon as adsorbent, whereas the adsorbate concentration of activated carbon reaches $0.42[\mathrm{~kg} / \mathrm{kg}]$. The variation of the adsorbate concentration by particles of the different adsorbents inside both the SGbed and AC-bed has been simulated and demonstrated versus the temperature along the cycle processes in Figure 8.
From this plot, the adsorbate concentration ratio $\mathrm{XSG}_{\mathrm{SG}}$ of SG-bed varies between its maximum value of 0.24 $\left[\mathrm{kg}_{\text {meth }} / \mathrm{kgsG}\right.$ ] to its minimum value of $0.11 \mathrm{kgmeth} / \mathrm{kgsG}$ during the cycle and the adsorbate concentration ratio $\mathrm{X}_{\mathrm{AC}}$ of $\mathrm{AC}$-bed varies between its maximum value of $0.42 \mathrm{~kg}$ meth $/ \mathrm{kg}_{A C}$ to its minimum value of 0.11 $\mathrm{kg}$ meth $/ \mathrm{kg}_{\mathrm{AC}}$ during the cycle.

Based on the properties of the adsorbents and calculations Eq. 1 and Eq. 2 it is found, the desorption/ adsorption process inside the AC-bed takes more time than that of Silica gel, therefore the first sorption reactor was filled by silica gel as adsorbent. The different characteristic times for adsorption and desorption processes during the SG-bed and the ACbed results from different mass transfer coefficient in Eq. 5.

Figure 9a shows plotting of the adsorbate concentration inside the SG-/AC-sorption reactor,

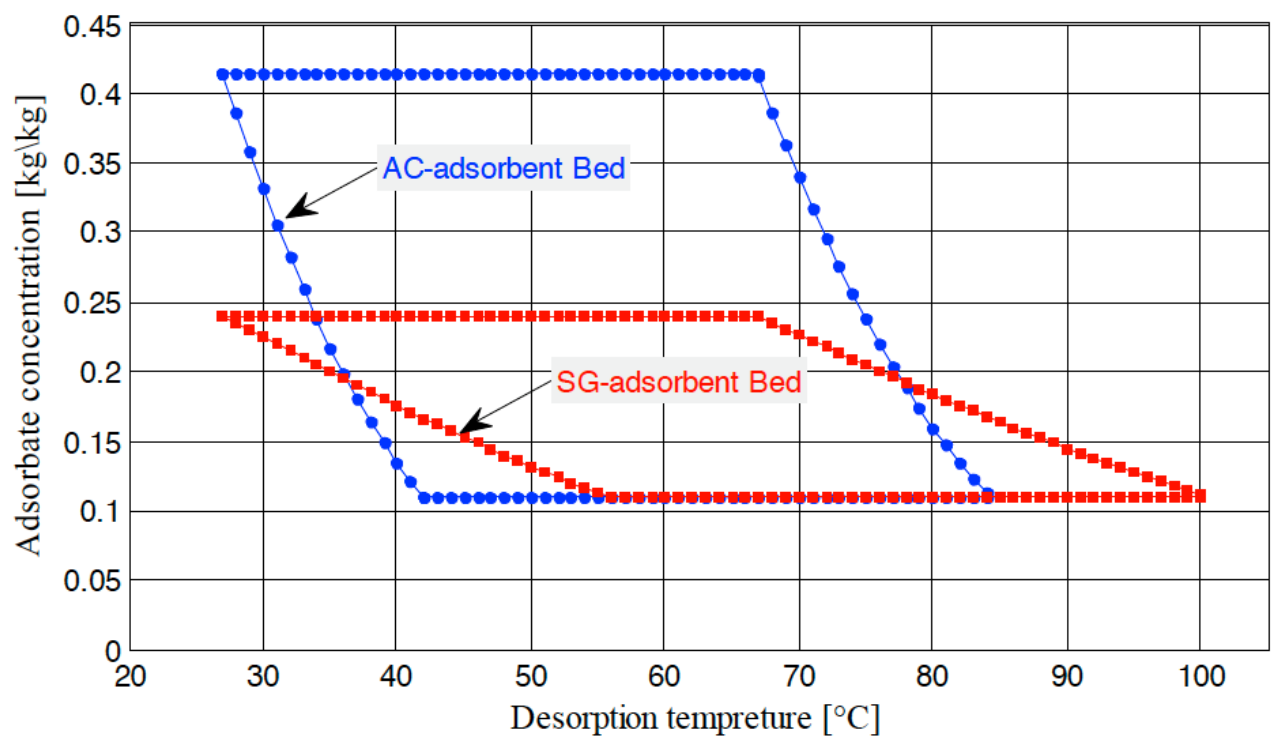

Figure 8: Variation of the adsorbate concentration with temperature along the cycle processes. 
which is demonstrated along the cycle time. Based on the simulation results which are calculated for $1 \mathrm{~kg}_{\text {meth }}$ of the desorbed refrigerant mass, it is found that the SG-bed reaches the end of desorption process faster than AC-bed.

As noticed from the Figure $\mathbf{9 b}$, the adsorbate mass is continuously varying throughout the cycle operations. No changes of the adsorbate refrigerant mass are observed during both isosteric preheating and precooling processes.

In the isobaric desorption phase, the desorbed methanol mass increases mref with temperature due to the decrease in refrigerant density with increasing temperature. During the isobaric heating process, the mass of the adsorbate phase (methanol) in the SGparticles $M_{a}^{S G}$ and in the AC-particles $M_{a}^{A C}$ are continuously decreasing since the refrigerant is being freed from the sorption reactor and flows towards the condenser. During the isobaric cooling process, the $M_{a}^{S G}$ and $M_{a}^{A C}$ are continuously increasing, because the refrigerant leaves from the evaporator and flows into the sorption reactor. Hence, the concentration ratio is continuously increasing along this process.
Figure $9 b$ shows variation of the adsorbate refrigerant mass inside both the SG- and AC-sorption reactor along the cycle time. The maximum and minimum values of the adsorbate concentration by SGbed correspond to a maximum and minimum contents of an adsorate mass of $1.9 \mathrm{~kg}$ and $0.9 \mathrm{~kg}$, respectively, whereas by AC-bed this corresponds to a maximum and minimum contents of an adsorbate mass of 1.36 $\mathrm{kg}$ and $0.36 \mathrm{~kg}$, respectively. As a result, the refrigerant mass utilization efficiency is estimated to be $73 \%$ by AC-bed and $53 \%$ by SG-bed, although $1 \mathrm{~kg}_{\text {meth }}$ circulated refrigerant mass was used for both cases. The results are simulated for $1 \mathrm{~kg}_{\text {meth }}$ of circulated refrigerant amount, therefore the minimum adsorbate concentration of SG-bed is limited by the heat source temperature $100{ }^{\circ} \mathrm{C}$ and the minimum adsorbate concentration of $\mathrm{AC}$-bed is limited by the heat source temperature $84{ }^{\circ} \mathrm{C}$.

\subsection{Variation of the Desorbed Refrigerant Mass}

Both the SG-bed and the AC-bed starts the generation (desorption) process at a temperature of about $67{ }^{\circ} \mathrm{C}$, but the SG-bed starts the adsorption process at a temperature of about $56{ }^{\circ} \mathrm{C}$, whereas the AC-bed starts that at a different temperature of $24{ }^{\circ} \mathrm{C}$.
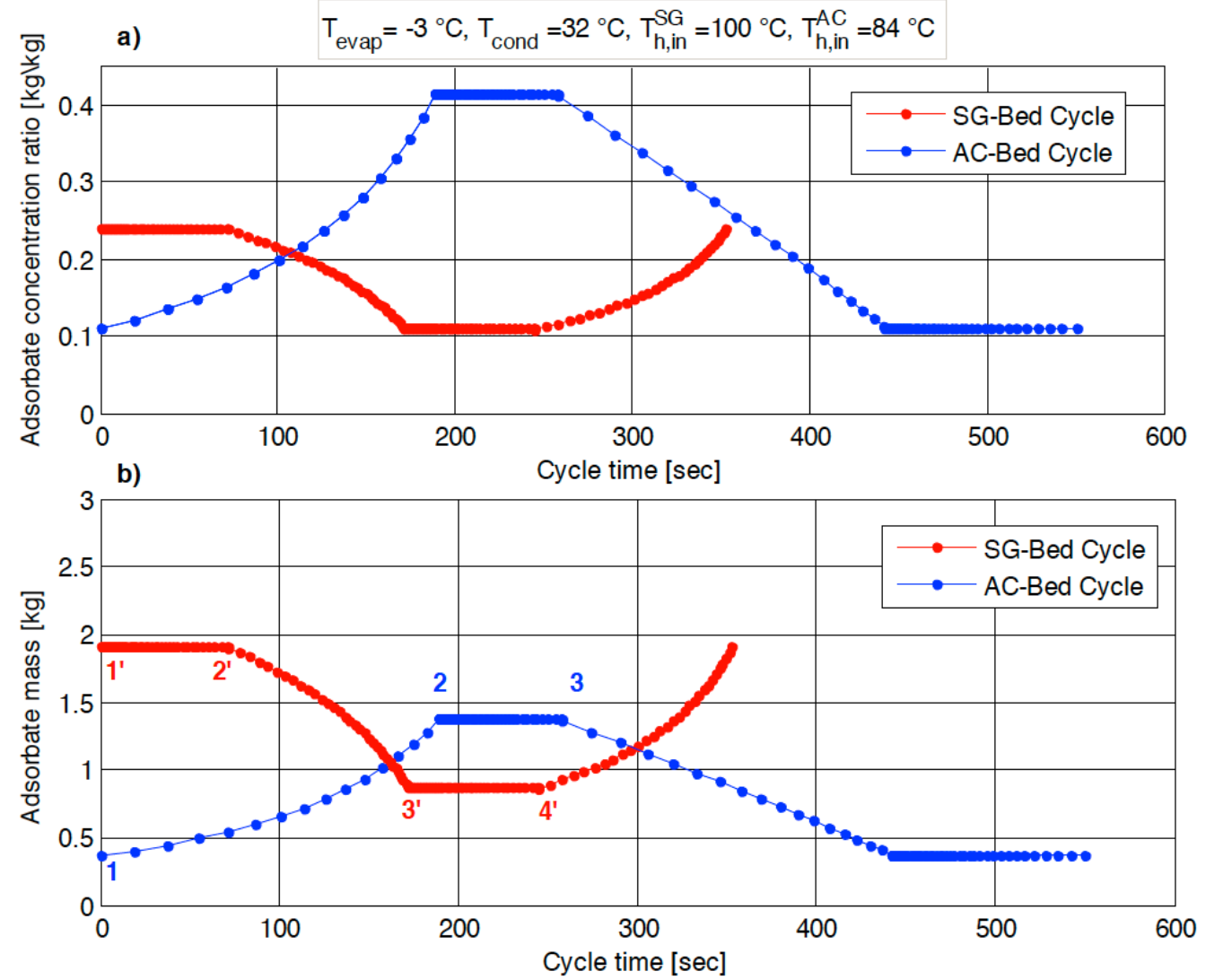

Figure 9(a): Variation of the adsorbate concentration ratio along the cycle time. (b): Variation of the adsorbate mass during cycle processes of SG-/AC-bed along the cycle time. 
The Figure 10 shows the evolution of the desorbed refrigerant mass that leaves the SG-particles and ACparticles with the temperature and along the time of the desorption process.

For operating the AIP system (SG-bed and AC-bed) at same the circulated refrigerant mass through the system of $1 \mathrm{~kg}$ meth, at same the evaporator temperature of $\mathrm{T}_{\mathrm{e}}=-3^{\circ} \mathrm{C}$ and at same the condenser temperature of $\mathrm{T}_{\mathrm{c}}=32{ }^{\circ} \mathrm{C}$ it is found, to desorb $1 \mathrm{~kg}_{\text {meth }}$ the SG-bed reaches the minimum value of the adsorbate concentration after a period of time about $100 \mathrm{sec}$ and during this process the SG-bed is heated up to the maximum desorption temperature of $100{ }^{\circ} \mathrm{C}$. Whereas to desorb the same masse of refrigerant $1 \mathrm{~kg}_{\text {meth }}$ the $\mathrm{AC}$-bed reaches the minimum value of the adsorbate concentration after $185 \mathrm{sec}$ and during this process the AC-bed is heated up to only $84^{\circ} \mathrm{C}$.

\subsection{Variation of the Adsorbed Refrigerant Mass}

The Figure 11 shows the variation of the adsorbed refrigerant mass from the SG-bed and from the ACbed. To adsorb $1 \mathrm{~kg}_{\text {meth }}$ of the methanol refrigerant the SG-bed starts with adsorption process at $56{ }^{\circ} \mathrm{C}$ and reaches the maximum value of adsorbate uptake $24 \%$ after $100 \mathrm{sec}$ at the ambient temperature of $27^{\circ} \mathrm{C}$. To adsorb the same mass of methanol refrigerant $1 \mathrm{~kg}_{\text {meth }}$ the AC-bed starts with adsorption process at $42{ }^{\circ} \mathrm{C}$ and reaches the maximum value of adsorbate uptake $42 \%$ after $185 \mathrm{sec}$ at the ambient temperature of $27^{\circ} \mathrm{C}$.

Based on the simulation results for desorption/ adsorption the refrigerant mass of $1 \mathrm{~kg}_{\mathrm{meth}}$, it is found that the SG-bed was filled by $1.9 \mathrm{~kg}$ of adsorbate liquid (methanol), whereas the AC-bed was filled only by 1.36 $\mathrm{kg}$. The time difference is mainly caused by the

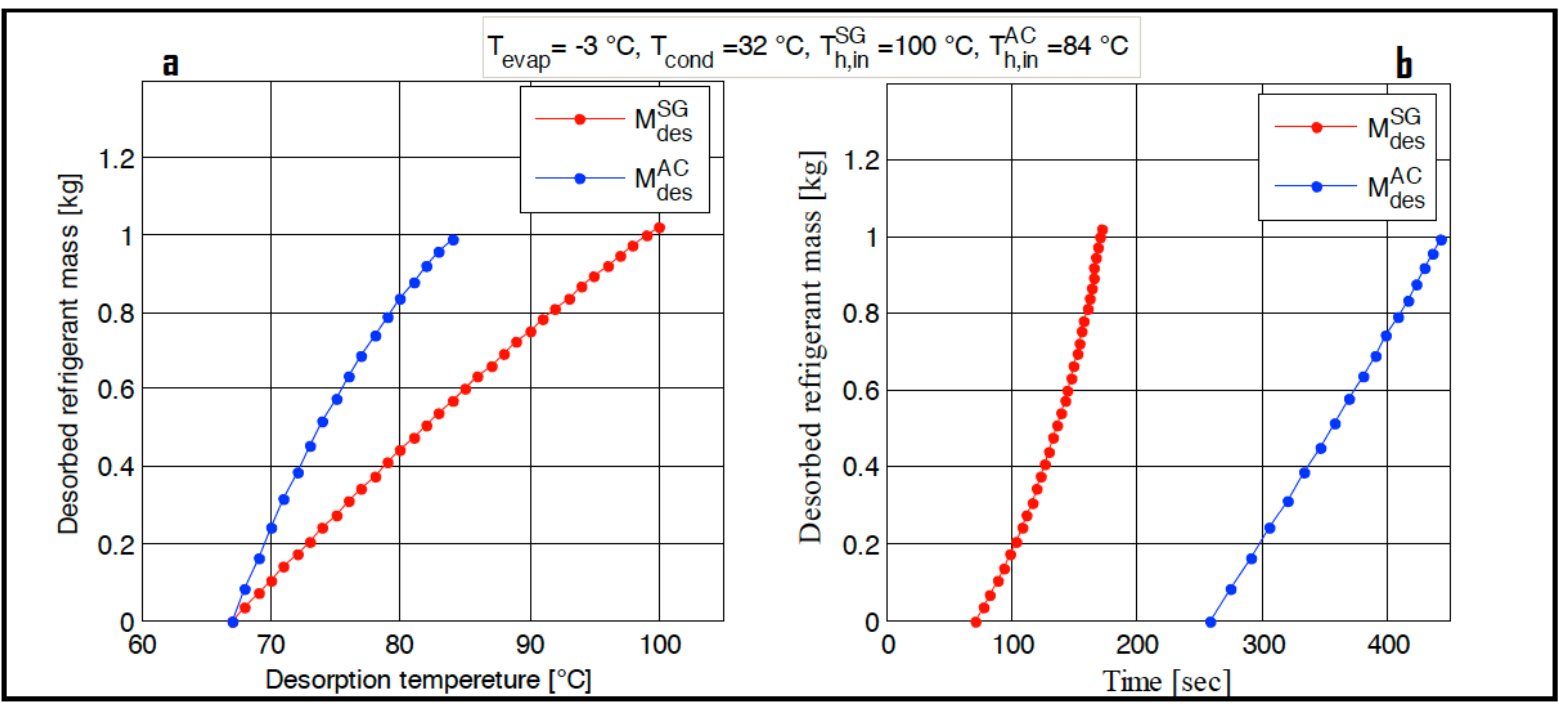

Figure 10: Evolution of the desorbed refrigerant mass during desorption process.

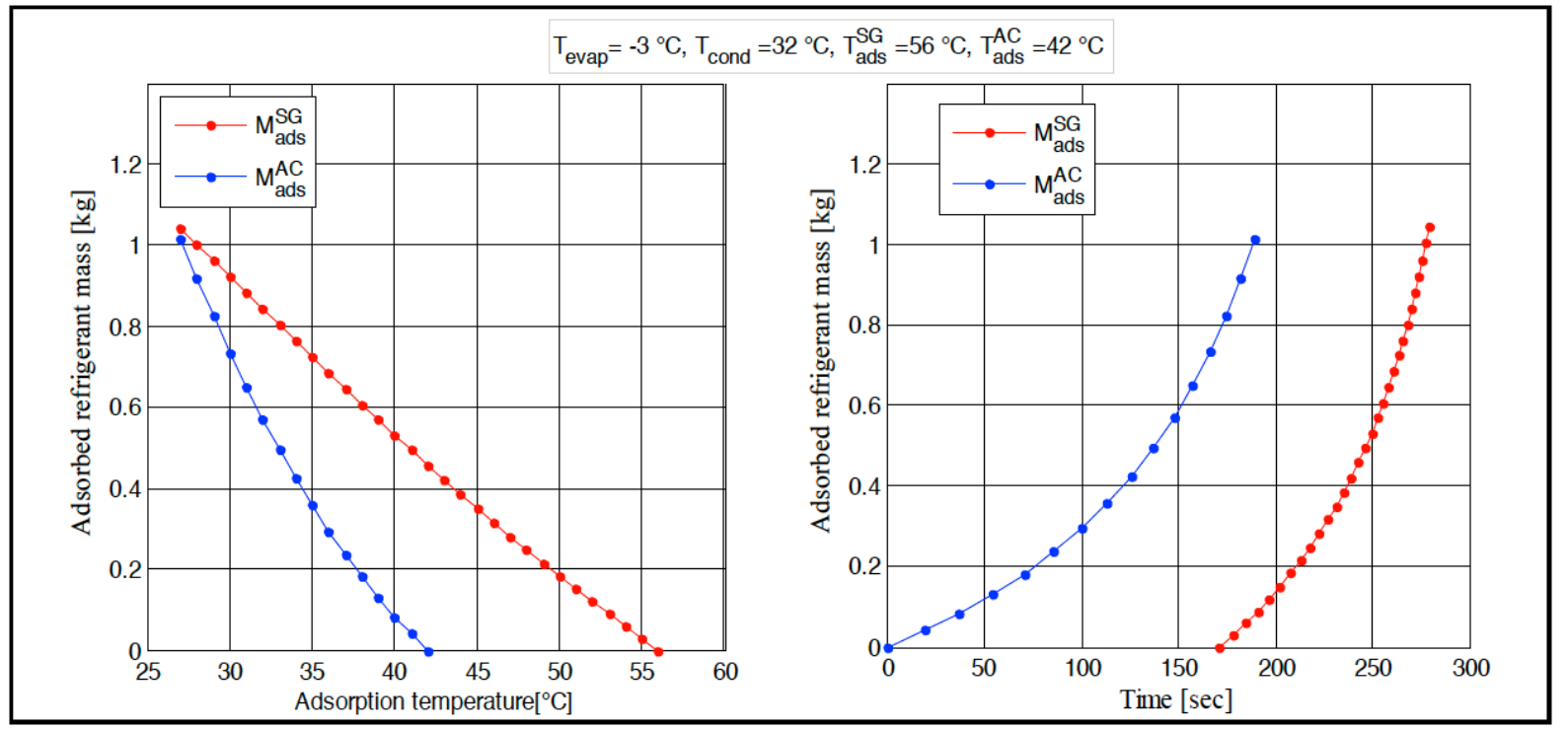

Figure 11: Evolution of the adsorbed refrigerant mass during adsorption process. 
temperature dependence of the mass transfer coefficient $D_{\text {so }}($ Eq. 4). Including the isosteric heating and cooling processes a complete cycle for SG-bed takes about $350 \mathrm{sec}$, whereas a complete cycle for ACbed takes about $550 \mathrm{sec}$.

\subsection{Effect of Desorption Temperature on COP and SCP}

Figure 12 shows the influence of desorption temperature on the two bed AIP system COP for the SG- and AC- bed. It is seen that COP increases as desorption temperature is increased. This is because the amount of refrigerant (methanol) circulated increases from 0 to $1 \mathrm{~kg}_{\text {meth }}$, due to increased refrigerant desorption with higher driving source temperature.

Nevertheless the desorbed methanol amount from SG-bed and from AC-bed is similar and the refrigeration energy produced $Q_{e}$ inside the evaporator estimated to $1200 \mathrm{~kJ}$ with using not only SG-bed but also AC-bed, it is found based on the simulation results, that the COP for the AIP system in case of using SG-bed at the selected point of operation $\left(T_{e}=-3\right.$ ${ }^{\circ} \mathrm{C}, \mathrm{T}_{\mathrm{C}}=32{ }^{\circ} \mathrm{C}, \mathrm{T}_{\mathrm{h} \text {,in }}=100{ }^{\circ} \mathrm{C}$ ) is about $44 \%$, whereas the COP for the AIP system using AC-bed at the selected point of operation $\left(\mathrm{T}_{\mathrm{e}}=-3{ }^{\circ} \mathrm{C}, \mathrm{T}_{\mathrm{c}}=32{ }^{\circ} \mathrm{C}, \mathrm{T}_{\mathrm{h}, \text { in }}=\right.$ $85^{\circ} \mathrm{C}$ ) is about $66 \%$.

The difference in the values of the coefficient performance for the AIP system is caused by variations in the driving energy required $Q_{\text {in }}$ by SG-sorption reactor and by AC-sorption reactor. To desorb $1 \mathrm{~kg}_{\text {meth }}$ of refrigerant mass, the driving energy required by SGbed is more than that required by $\mathrm{AC}$-bed. This is because the SG-bed must been heated up to desorption temperature of $100{ }^{\circ} \mathrm{C}$, whereas the SG-bed must be heated up to $84{ }^{\circ} \mathrm{C}$ from $\mathrm{AC}$-bed.

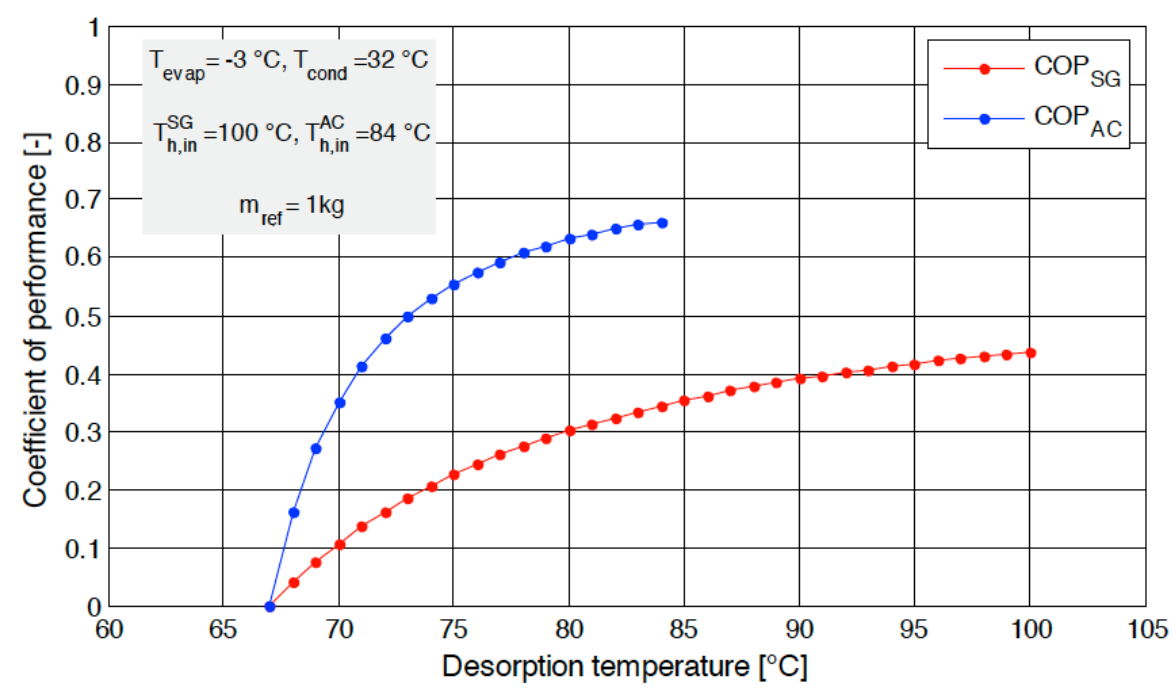

Figure 12: Effect of the desorption temperature on the coefficient performance of the AIP system.

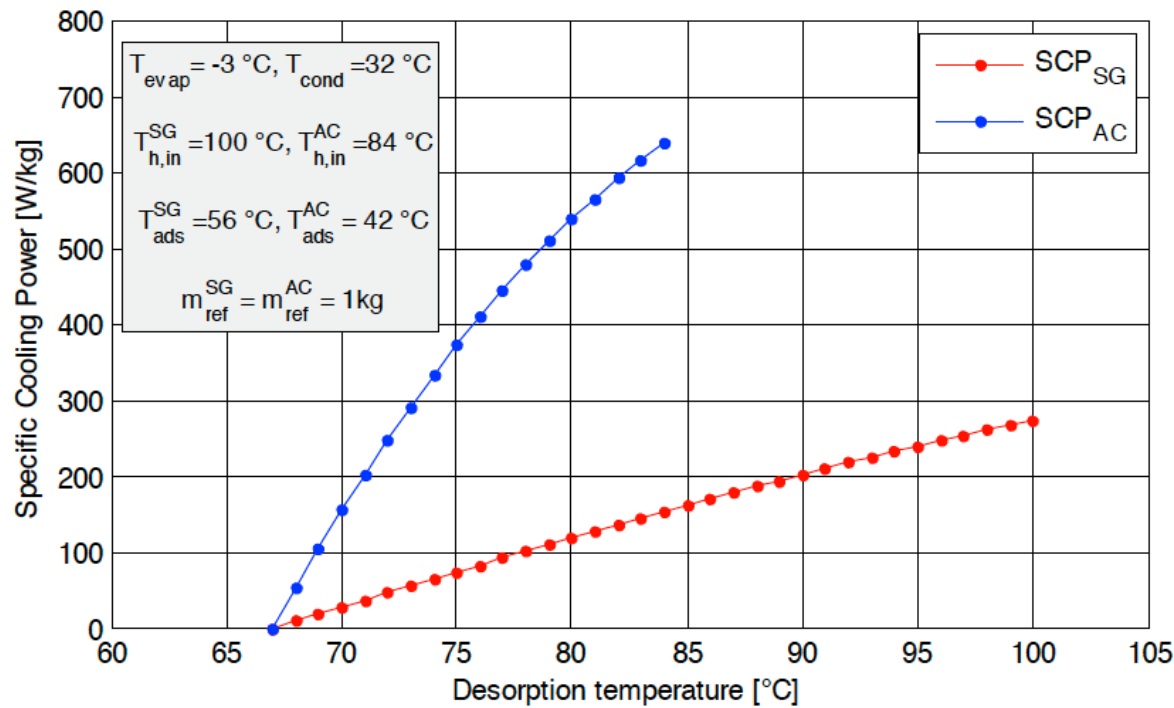

Figure 13: Effect of the desorption temperature on the specific cooling power of the AIP system. 
In Figure 13 the specific cooling power SCP is depicted with the variation of desorption temperature inside both the $S G$ and $A C$ sorption reactor. It is seen that SCP of the proposed cycle is also increased with increase of desorption temperature as we observed for COP. Although the sorption kinetic with silica gel is faster, the much higher power density SCP of the AIP system is mainly reached by activated carbon. This is because the density of the sorption material, which affects the used amount of adsorbent.

It is found the amount of activated carbon is smaller than the amount of silica gel to desorb or adsorb the same circulated refrigerant through the AIP system. SCP is Inversely proportional to $M_{s}$ the amount of the sorption material Eq. 12.

\subsection{The Amount of Produced Ice and the Refrigeration Capacity}

From Figure 14, it can be seen the refrigeration capacity $\dot{Q}_{e}$ increases with an increase in $\mathrm{T}_{\text {des. }}$. When desorption temperature increases, the cycle refrigerant mass mref will increase and the evaporative refrigeration energy $Q_{e}$ produced in the evaporator will increase.

Whereas the amount of circulated refrigerant mass through the AIP system is same for both adsorbents, the resulting refrigeration energy $Q_{e}$ is same due to the same heat of vaporization which corresponds to the same refrigerant (methanol) by the different adsorbents and the same evaporator temperature Eq. 8. But the refrigeration capacity $\dot{Q}_{e}[k W]$ is different. This is

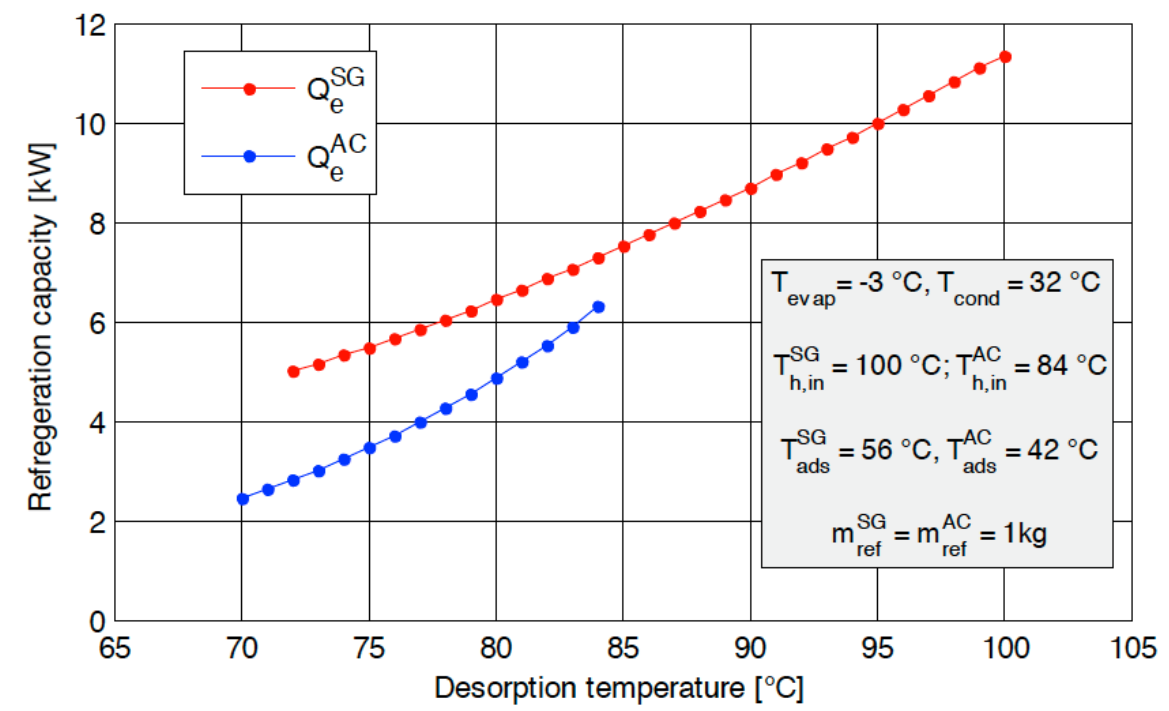

Figure 14: Effect of the desorption temperature on the refrigeration capacity of the AIP system.

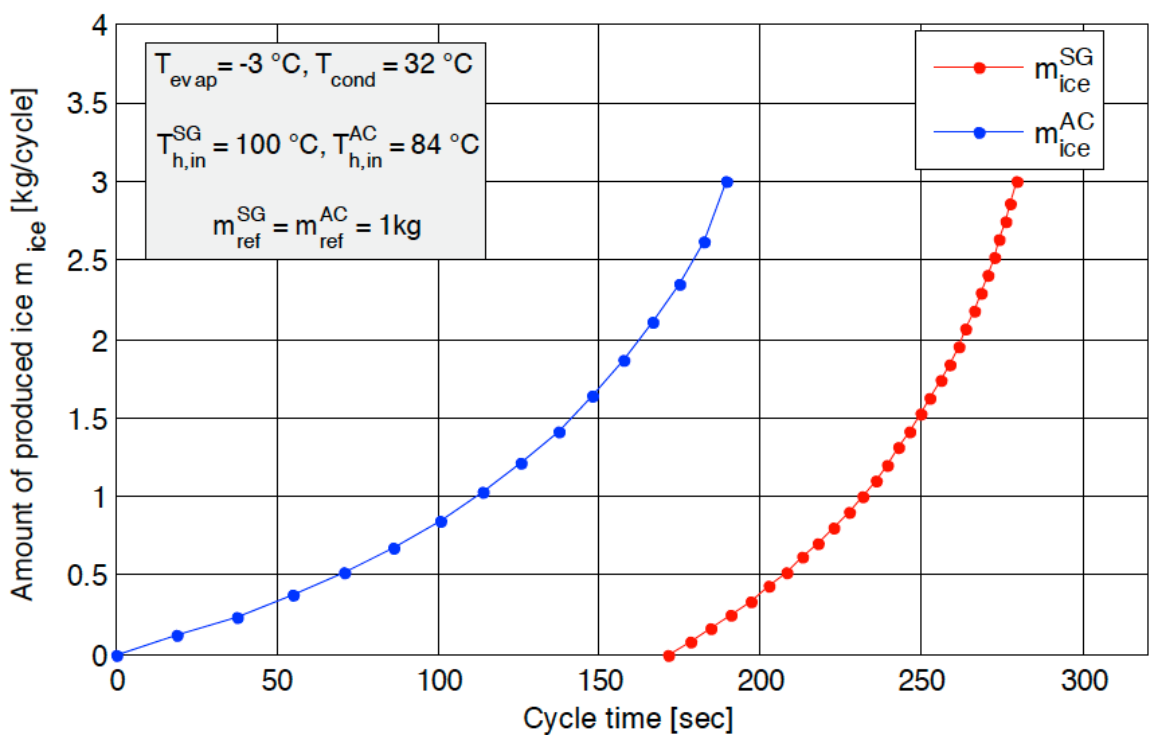

Figure 15: Evolution of the amount of ice produced during the time of one cycle. 
caused by the different adsorption time. SG-bed takes about half of the adsorption time for the AC-bed. Comparing the resulting refrigeration capacity from the SG-bed with the results from the AC-bed shows that $\dot{Q}_{e}{ }^{S G}$ is about $11.34 \mathrm{~kW}$, whereas $\dot{Q}_{e}{ }^{A C}$ is only $6.29 \mathrm{~kW}$.

The Eq. 11 shows that the ice produced is proportional to the refrigeration energy. The amount of ice produced per one complete cycle of the AIP system is shown in the Figure 15.

If the SG-bed or the AC-bed works, the system produces the same mass of ice of $3 \mathrm{~kg}$ at $-3{ }^{\circ} \mathrm{C}$ from water at a source temperature of $15{ }^{\circ} \mathrm{C}$. Therefore the amount of the ice produced from this system estimated to $6 \mathrm{~kg}$ per cycle. Based on the simulation results it is found, that every $1 \mathrm{~kg}$ of silica gel-particles inside the SG-sorption reactor produces ice mass of $0.38 \mathrm{~kg}$ per cycle under the hot water inlet temperature of $100{ }^{\circ} \mathrm{C}$. and every $1 \mathrm{~kg}$ of activated carbon-particles inside the AC-sorption reactor produces ice mass of $0.9 \mathrm{~kg}$ per cycle under the hot water inlet temperature of $84^{\circ} \mathrm{C}$.

The amount of produced ice is shown in Figure 16 versus the desorption temperature for a given inlet chilled water temperature $T_{c h, i n}$. As a result of using this technique we can note that AIP-system works effectively, because the increasing the inlet chilled water temperature slightly reduces the rate of increase in the amount of produced ice. As noticed from the Figure 16, the decrease in the amount of ice produced per cycle with variation of the inlet chilled water temperature from $15{ }^{\circ} \mathrm{C}$ to $25{ }^{\circ} \mathrm{C}$ is estimated to be $11 \%$ by AC-cycle and $9 \%$ by SG-cycle.

\section{SUMMARY AND CONCLUSIONS}

The theoretical and thermodynamic investigation of the two bed AIP system that works using silica gelmethanol in the first sorption bed and activated carbonmethanol in the second bed was done to improve the refrigeration capacity and save the driving energy based on using the advantages of physical properties of both adsorbents SG and AC. To achieve that, two finned tube- heat exchangers for each sorption reactor are investigated to desorb/adsorb the same amount of the refrigerant (methanol). The analytical model was simulated using MATLAB software.

This two bed AIP system can utilize the fluctuated heat source temperature between 65 and $100{ }^{\circ} \mathrm{C}$ to produce effective cold (ice) along with a coolant inlet from 15 to $25^{\circ} \mathrm{C}$. The main feature of the proposed AIP system is the ability to be driven by relatively low temperature heat source. Simulation results showed that the heat exchanger filled with AC particles can save the input energy from heat source about $46 \%$ and the heat exchanger filled with SG particles takes about half of the desorption/adsorption time compared with the AC-bed to desorb or adsorb the same amount of the circulated methanol through the system. The analysis of the cooling processes and adsorption/ desorption processes for two sorption reactor theoretical were simulated by using $3.31 \mathrm{~kg}$ of activated carbon, $1.36 \mathrm{~kg}$ of methanol in the AC-sorption reactor of $2.67 \mathrm{~m}^{2}$ heat transfer area and by using $7.95 \mathrm{~kg}$ of silica gel, $1.9 \mathrm{~kg}$ of methanol in the SG-sorption reactor of $5.34 \mathrm{~m}^{2}$ heat transfer area.

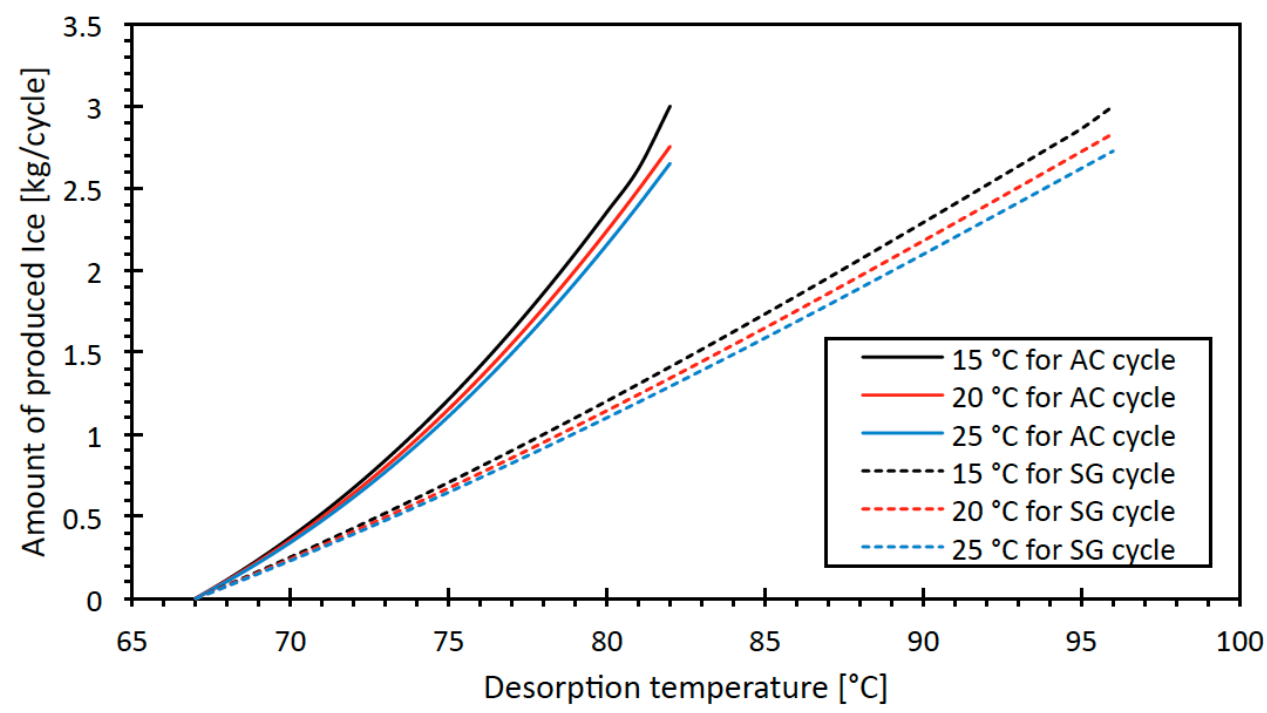

Figure 16: Effect of inlet chilled water and desorption temperature on the amount of ice produced. 
The simulation results showed that $6 \mathrm{~kg}$ of ice per cycle could be produced from this AIP system $3 \mathrm{~kg}$ of ice, produced in case the AC-sorption reactor is working, could be obtained with a COP equals 0.66 under the hot water inlet temperature of $84{ }^{\circ} \mathrm{C}$ whereas the evaporation temperature of $-3{ }^{\circ} \mathrm{C}$. This amount of ice produced is also $3 \mathrm{~kg}$ with using SG- sorption reactor but the system in this case attains a coefficient of performance COP of $44 \%$ under the hot water inlet temperature of $100{ }^{\circ} \mathrm{C}$ whereas the evaporation temperature of $-3{ }^{\circ} \mathrm{C}$. Nevertheless the SG-bed is heated up along the isobaric desorption to $100{ }^{\circ} \mathrm{C}$ and AC-bed to $85{ }^{\circ} \mathrm{C}$, the desorption process during the AC-bed takes more time about $185 \mathrm{sec}$, whereas this process takes time about $100 \mathrm{sec}$ during SG-bed. Comparing the resulting refrigeration capacity from the SG-bed with the results from the AC-bed shows that the is about $11.34 \mathrm{~kW}$, whereas the is only $6.29 \mathrm{~kW}$.

Nevertheless the SG-bed takes less time for the desorption/adsorption compared with the AC-bed, the integral heating energy required during one cycle is higher by for the SG-bed. This is because of the physical properties of silica gel as adsorbent compared with the physical properties of activated carbon such as the activation energy $\mathrm{Ea}[\mathrm{kJ} / \mathrm{kg}]$ and the mass transfer coefficient $D_{s o}[1 / \mathrm{sec}]$. Consequently, The utilization of silica gel and activated carbon as adsorbents together in an adsorption machine make it possible to increase the desorbed mass rate of refrigerant and hence it has the potential to provide higher refrigeration capacity and to produce continuous amount of ice.

\section{HIGHLIGHTS}

- $\quad$ The AIP system in this study comprises with two sorption reactors, that the first sorption reactor was filled by silica gel and the second sorption reactor by activated carbon. Methanol was used as adsorbate and refrigerant with both the beds.

- The theoretical and thermodynamic investigation of the two bed AIP system was done to improve the refrigeration capacity and save the driving energy based on using the advantages of physical properties of both adsorbents SG and AC. To achieve that, two finned tube- heat exchangers for each sorption reactor are investigated to desorb/adsorb the same amount of the refrigerant (methanol).
- $\quad$ The results showed, that the AIP system attains a coefficient of performance COP of $66 \%$ when the AC-bed is working and attains of $44 \%$ when the SG-bed is working. The amount of the ice produced from the system estimated to $6 \mathrm{~kg}$ per cycle ( $3 \mathrm{~kg}$ is produced from each of bed).

\section{ACKNOWLEDGEMENTS}

The author wish to thank the IImenau University (IImenau-Germany), Hochschule Ostwestfalen-Lippe (Höxter-Germany) and AL-Baath University (Syria) for the financial support on this study.

\section{REFERENCES}

[1] Fernandes MS, Brites GJVN, Costa JJ, Gaspar AR and Costa VAF. Review and future trends of solar adsorption refrigeration systems. Renew Sust Energy Rev 2014; 39: 102-123. https://doi.org/10.1016/j.rser.2014.07.081

[2] Douss $\mathrm{N}$ and Meunier $\mathrm{F}$. Experimental study of cascading adsorption cycles. Chem Eng Sci 1989; 44 (2): 225-235. https://doi.org/10.1016/0009-2509(89)85060-2

[3] Chua HT, Ng KC, Malek A, Kashiwagi T, Akisawa A, Saha BB. Modeling the performance of two-bed silica Gel-water adsorption chillers. Int J Refrig 1999; 22: 194-204. https://doi.org/10.1016/S0140-7007(98)00063-2

[4] Gregg SJ, Sing KSW. Adsorption, surface area and porosity. 2nd ed. Academic press, London 1982.

[5] Rezk ARM. Theoretical and experimental investigation of silica gel-water adsorption. 2012. A thesis submitted of the university of Birmingham for the degree of Doctor of Philosophy.

[6] Amir S, Majid B. Assessment of adsorber bed designs in waste-heat driven adsorption cooling system for vehicle air conditioning and refrigeration. Renew Sust Energy Rev 2014; 30: 440-451.

https://doi.org/10.1016/i.rser.2013.10.031

[7] Gong LX, Wang RZ, Xia ZZ, Lu ZS. Experimental study on an adsorption chiller employing lithium chloride in silica gel and methanol. Int J Refrig 2012; 35: 1950-1957. https://doi.org/10.1016/j.ijrefrig.2012.06.013

[8] Wang RZ, Oliveira RG. Adsorption refrigeration an efficient way to make good use of waste heat and solar energy. International sorption heat pump conference, June 22-24, 2005; Denver, Co, USA

[9] Solmus I, Yamali C, Kaftanoglu B, Baker D, Caglar A Adsorption properties of a nature zeolite-water pair for use in adsorption cooling cycles. Applied Energy 2010; 87: 20622067. https://doi.org/10.1016/j.apenergy.2009.11.027

[10] Oertel K, Fischer M. Adsorption cooling system for cold storage using methanol/silicagel. Appl Thermal Eng 1998; 18: 773-786.

https://doi.org/10.1016/S1359-4311(97)00107-5

[11] Ogueke NV, Anyanwu EE. The performance analysis of a solid adsorption solar refrigerator during collector cool-down and refrigerant evaporation/re-adsorption phases. J Proc Mech Eng 2009; 223 (1): 11-19.

https://doi.org/10.1243/09544089JPME217

[12] Khan MZI, Sultan S, Akisawa A, Kashiwagi T. Numerical simulation of advanced adsorption refrigeration chiller with mass recovery. J Navel Arch Marine Eng 2006; 3: 59-67. 
[13] Cho SH, Kim JN. Modeling of a silica gel/water adsorption cooling system. Energy 1992; 17 (9): 829-839. https://doi.org/10.1016/0360-5442(92)90101-5

[14] Qasem NAA, El-Shaarawi MAI. Thermal analysis and modeling study of an activated carbon solar adsorption icemaker: Dhahran case study. Energy Conversion and Management 2015; 100: 310-323.

https://doi.org/10.1016/j.enconman.2015.04.054

[15] Liu Y, Leong KC. The effect of operating conditions on the performance of zeolite/water adsorption cooling systems. Appl Thermal Eng 2005; 25: 1403-1418. https://doi.org/10.1016/j.applthermaleng.2004.09.013

[16] Hassan HZ. Energy analysis and performance evaluation of the adsorption refrigeration system. ISRN Mechanical Engineering, Article ID 704340 (2013) 1-14.

[17] Jribi S, Miyazaki T, Saha BB. Koyama S. Transient simulation of finned tube type adsorber employing activated carbonethanol as adsorbent refrigerant pair. ICR 2015, August 16 22 - Yokohama, Japan.

[18] Goodwin RD. Methanol Thermodynamic Properties from 176 to $673 \mathrm{~K}$ at pressures to 700 bar. Thermophysics Division, National Engineering Laboratory, National Bureau of Standards, Colorado 80303 (1987).

[19] Li M, Wang RZ. Heat and mass transfer in a flat plate solar solid adsorption refrigeration ice maker. Renewable Energy 2003; 28: 613-622. https://doi.org/10.1016/S0960-1481(02)00094-0

[20] Gong LX, Wang RZ, Xia ZZ, Lu ZS. Experimental study on an adsorption chiller employing lithium chloride in silica gel and methanol. Int J Refrig 2012; 35: 1950-1957. https://doi.org/10.1016/j.ijrefrig.2012.06.013

[21] El-Sharkawy II. Study on adsorption of methanol onto carbon based adsorbents. Int J Refrig 2009; 32: 1579-1586. https://doi.org/10.1016/j.jirefrig.2009.06.011

[22] $\mathrm{Ng} \mathrm{KC}$, Chua HT, Chung $\mathrm{CY}$, Loke $\mathrm{CH}$, Kashiwagi T, Akisawa A, Saha BB. Experimental investigation of the silica gel-water adsorption isotherm characteristics. Appl Thermal Eng 2001; 21: 1631-1642. https://doi.org/10.1016/S1359-4311(01)00039-4

[23] Hasan HZ, Mohamad AA, Alyousef $Y$ and Al-Ansary HA. A review on the equation of state for the working pairs used in adsorption cooling systems. Renew Sust Energy Rev 2015; 45: 600-608. https://doi.org/10.1016/j.rser.2015.02.008

[24] Wang LW, Wang RZ and Oliveira RG. A review on adsorption working pairs for refrigeration. Renew Sust Energy Rev 2009; 13 (3): 518-534. https://doi.org/10.1016/j.rser.2007.12.002

[25] Srivastava NC and Eames IW. A review of adsorbents and adsorbates in solid-vapour adsorption heat pump systems. Appl Thermal Eng 1998; 18: 707-714. https://doi.org/10.1016/S1359-4311(97)00106-3

[26] Ali M and Ajib S. Energy analysis and modeling study of combined activated carbon-silica gel/methanol adsorption ice production system. Glob J Energ Technol Res Updat 2016; 3; 1-22.

https://doi.org/10.15377/2409-5818.2016.03.01.1

Received on 22-03-2017

Accepted on 07-04-2017

Published on 21-06-2017

\section{DOI: http://dx.doi.org/10.15377/2409-5818.2017.04.01.2}

(C) 2017 Majd Ali et al.; Avanti Publishers.

This is an open access article licensed under the terms of the Creative Commons Attribution Non-Commercial License (http://creativecommons.org/licenses/by-nc/3.0/) which permits unrestricted, non-commercial use, distribution and reproduction in any medium, provided the work is properly cited. 